\title{
Epitaxial lanthanide oxide thin films on Si for high- $k$ gate dielectric application: Growth optimization and defect passivation
}

\author{
Ayan Roy Chaudhuria) \\ Materials Science Centre, Indian Institute of Technology, Kharagpur 721302, India \\ Andrea Fissel and Hans Jörg Osten \\ Institute of Electronic Materials and Devices, Leibniz University Hannover, D-30167 Hannover, Germany
}

(Received 31 August 2016; accepted 4 January 2017)

\begin{abstract}
Epitaxial layers of insulating binary lanthanide oxides have been considered as potential alternative to conventional $\mathrm{SiO}_{2}$ for gate dielectric application in future Si-based MOSFET devices, which was investigated in more detail for epitaxial $\mathrm{Gd}_{2} \mathrm{O}_{3}$ and $\mathrm{Nd}_{2} \mathrm{O}_{3}$ as model systems. Additionally, the ability to integrate epitaxial dielectric barrier layers into Si structures can usher also in a variety of novel applications involving oxide/silicon/oxide heterostructures in diverse nanoelectronic and quantum-effect devices. Although epitaxial layers of such ionic oxides with excellent structural quality can be grown using molecular beam epitaxy, they often exhibit poor electrical properties such as high leakage current density, flat band instability, poor reliability etc. owing to the presence of electrically active charge defects, generated either during the oxide layer growth or typical subsequent CMOS process steps. Based on the origin and individual character of these defects, we review various aspects of defect prevention and passivation which lead to a significant improvement in the dielectric properties of the heterostructures.
\end{abstract}

\section{INTRODUCTION}

The physical dimension of metal oxide field effect transistors (MOSFETs) which are essential components of semiconductor integrated circuits (ICs) have been subjected to continuous downscaling since the birth of ICs to improve the device performance and reduce the production cost per bit. This shrinking of the semiconductor device dimension follows an empirical trend popularly known as Moore's law, which describes that the number of transistors per IC, or in other words processing capacity and speed doubles, every two years. ${ }^{1}$ Moore's prediction was found true for a long while thanks to the rapid advancement of semiconductor device processing technologies such as lithography, selective etching processes etc. On the other hand from the materials aspect, the key material property that enabled the existence of Si-MOSFET devices is the excellent insulating characteristic of $\mathrm{SiO}_{2}$ thin layers which is used as the gate dielectric to isolate the transistor gate from the $\mathrm{Si}$ channel. This is possible due to the large band gap of $\mathrm{SiO}_{2}\left(E_{\mathrm{g}} \sim 9 \mathrm{eV}\right)$, and the low density of interface traps with $\mathrm{Si}$. For example, in advanced integrated devices $\mathrm{SiO}_{2}$ gate dielectrics with charge densities of $10^{10} \mathrm{~cm}^{-2}$, midgap interface state densities of $10^{10} \mathrm{~cm}^{-2}$, and dielectric strength of

\footnotetext{
Contributing Editor: Don W. Shaw

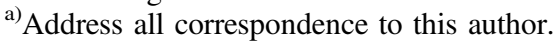

e-mail: ayan@matsc.iitkgp.ernet.in

This paper has been selected as an Invited Feature Paper.

DOI: $10.1557 / \mathrm{jmr} .2017 .22$
}

$15 \mathrm{kV} / \mathrm{cm}$ have been produced. ${ }^{2,3}$ Further, high quality layer of $\mathrm{SiO}_{2}$ can be grown by simple thermal oxidation that remains amorphous at typical CMOS process condition which is less prone to any structural defects. However, it was evident that continuing the device scaling as per Moore's law cannot be pushed longer if $\mathrm{SiO}_{2}$ has to be used further as the gate dielectric. The primary disadvantage of using $\mathrm{SiO}_{2}$ as the gate dielectric is its relatively low dielectric constant $(k-3.9)$. This imposes significant reduction in the thickness of the $\mathrm{SiO}_{2}$ layer as a consequence of downscaling the MOSFET devices to achieve higher gate capacitance necessary to produce the required drive current in submicron MOSFETs. For example, the specific gate capacitance used for todays CMOS technology nodes demands $\mathrm{SiO}_{2}$ thickness $<1 \mathrm{~nm}$. Unfortunately, such ultrathin layers of $\mathrm{SiO}_{2}$ cannot act really as an insulator, as direct tunneling through the dielectric barrier dominates the conduction behavior and the leakage current increases exponentially with decreasing gate dielectric layer thickness. ${ }^{4}$ For example, scaling of the gate oxide below $1 \mathrm{~nm}$ leads to leakage current density of $\sim 10 \mathrm{~A} / \mathrm{cm}^{2}$ at $1 \mathrm{~V}$ which is beyond the acceptable limit for low power device applications. It has also been demonstrated that fabricating CMOS devices with $\mathrm{SiO}_{2}$ layer thickness in the range of 1.0-1.2 nm does not lead to any further gain in the drive current setting a fundamental limit for gate oxide scaling. ${ }^{5}$ Moreover, in contrast to high performance microprocessors, the leakage current densities of transistors in case of low power consumption devices should be well below $10^{-1} \mathrm{~A} / \mathrm{cm}^{2},{ }^{6}$ making the gate oxide thickness 
issue more stringent. There have been additional limiting factors to $\mathrm{SiO}_{2}$ scaling, such as boron diffusion from traditional highly doped poly-Si to lightly doped channel layer $^{7}$ that results in shift in the transistor threshold voltage and degraded device reliability owing to hot electron injection at the $\mathrm{Si}-\mathrm{SiO}_{2}$ interface causing dielectric breakdown of the gate oxide. ${ }^{8}$ These issues related to material limited device scaling is most prominent in case of MOSFETs than in any other device components and became the showstopper in the historical progress of multibillion semiconductor industry. ${ }^{2}$ In this context, one of the major challenge associated with further scaling of integrated devices was to find suitable replacement gate insulator material that possesses higher dielectric constant than $\mathrm{SiO}_{2}$ and therefore can be grown with larger thickness which shall allow sufficient FET current drive while maintaining lower leakage current. ${ }^{9}$

\section{CHOICE OF ALTERNATIVE GATE INSULATOR}

$\mathrm{SiO}_{2}$ is the key material that laid the foundation of $\mathrm{Si}$ based microelectronics technology and led it to flourish despite the average performance of Si compared to other semiconductors, such as $\mathrm{Ge}, \mathrm{GaAs}, \mathrm{GaN}, \mathrm{SiC}$, etc. which do not form a thermally stable native oxide. Integrating an alternative dielectric to $\mathrm{Si}$ would be possible only at the expense of the advantages of $\mathrm{SiO}_{2}$, which makes the choice of alternative gate dielectric a critical issue. The semiconductor industry first found interim solution remaining within the $\mathrm{Si}-\mathrm{SiO}_{2}$ materials framework by selecting silicon oxynitride and oxide/nitride stacks as alternative gate dielectrics which offer slightly higher $k$ value compared to $\mathrm{SiO}_{2}$ and thus lead to reduced leakage, boron penetration, and reliability issues by using relatively larger gate dielectric layer thickness. ${ }^{10}$ However, this was only a temporary solution as incorporation of increasing amount of $\mathrm{N}$ gives rise to side effects, such as severe degradation of electron mobility in the transistor channel and reduced band gap of the oxide. ${ }^{8}$ Therefore, the search of really alternative dielectric materials with much higher dielectric constant was on the agenda to keep pace with the historical steep progress of $\mathrm{Si}$ technology. The first parameter to be considered for selecting an alternative material is the appropriate value of the dielectric constant that can be useful for transistor application. While leakage current through the dielectric layer in the direct tunnel regime depends exponentially on its thickness, the capacitance varies linearly. Consequently, dielectrics with too high dielectric constant lead to short channel performance degradation, owing to the fringing field from the gate to source/drain region due to large thickness to length aspect ratio of the gate dielectric. ${ }^{11}$ Optimum $k$ values within the range of 15 and 50 are predicted to be ideal for continuing scaling of transistors in the future, which shall be applicable for both low standby power and high performance devices. ${ }^{9}$ Besides suitable higher $k$ value, any material selected as alternative to substitute $\mathrm{SiO}_{2}$ as gate dielectric will also have to satisfy several other criteria to be eligible for gate dielectric application, such as thermodynamic stability in direct contact with $\mathrm{Si}$, thermal stability even at typical CMOS process temperatures of up to $1000{ }^{\circ} \mathrm{C}$, large band gap, low bulk defect density, low interfacial trap densities, CMOS process compatibility and reliability. ${ }^{2}$

A wide variety of insulating metal oxides with much higher $k$ values has been investigated in the past decade as viable alternative to Si-oxynitride and oxide/nitride systems. Many of these metal oxide alternative dielectrics appear to satisfy some of these requirements, but unfortunately only a very few materials are promising with respect to all of the guidelines. Furthermore, the process complexity associated with deposition of the high- $k$ metal oxides in contrast to simple thermal deposition of $\mathrm{SiO}_{2}$ and oxynitrides pose additional challenges for integrating the alternative dielectrics into mainstream Si technology, such as cost of the deposition tools for large scale production with proper stoichiometry and satisfactory microstructure control, in addition to the requirement of using metal gates, etching and related aspects. ${ }^{12}$

Different binary metal oxides have been considered promising because of the relative ease in controlling the stoichiometry in their thin films. But a number of these oxides are not stable in contact with $\mathrm{Si}$ at $T>1000 \mathrm{~K}$ and gives rise to an interfacial layer formation. ${ }^{13}$ Interfacial layer exhibiting lower $k$ value eventually leads to degradation of the effective dielectric constant and limits the scalability of the device. Another critical parameter to consider is the band gap of the metal oxides, which is mostly much smaller than that of $\mathrm{SiO}_{2}(\sim 9 \mathrm{eV})$, that directly influences their conduction band and valence band offset (VBO) energies with respect to $\mathrm{Si}$. This is related to the ionic character of the metal oxides in contrast to covalent $\mathrm{SiO}_{2}$. A number of representative dielectric oxides have been found to obey an approximate inverse relation between their static dielectric constant and band gap. This behavior is expected because stronger polarizability implies weaker bonding which leads to smaller separation in bonding and antibonding energies. ${ }^{14}$ The band offsets, which determine the electron and hole injection barriers respectively at the oxide/Si interface, should be at least $1 \mathrm{eV}$ (for both conduction and valence bands) to prevent charge carrier injection from $\mathrm{Si}$ into the bands of the chosen oxide. ${ }^{15}$ Figure 1 illustrates the calculated band offsets of several promising high- $k$ dielectric oxides with respect to $\mathrm{Si}$. It is clearly evident that only a few of the high $k$ oxides are suitable candidates for gate dielectric application, despite superior dielectric constant values of several other oxides.

An additional roadblock for integrating high- $k$ metal oxides into Si technology is their lower crystallization 


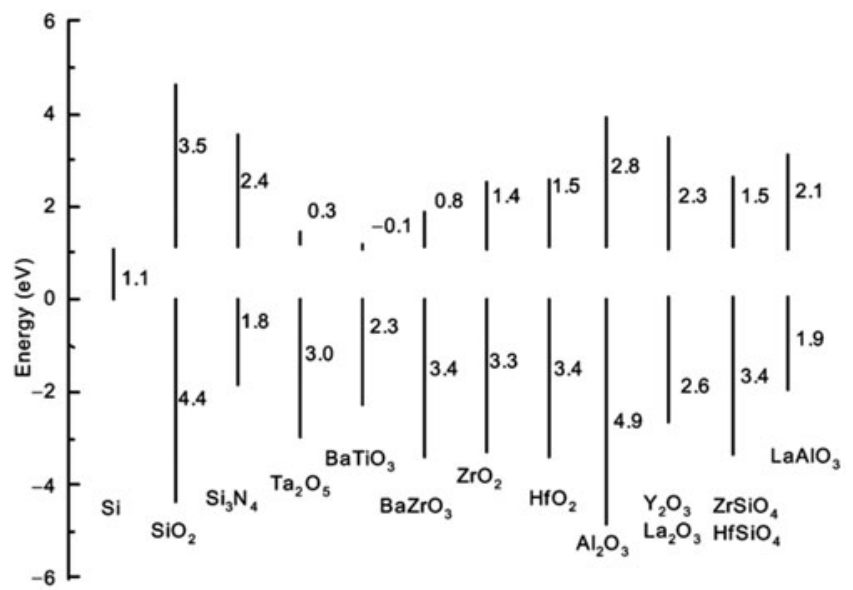

FIG. 1. Calculated conduction band and valence band offsets of various oxides on $\mathrm{Si}$. (Reprinted with permission from Ref. 15. Copyright [2000], American Vacuum Society).

temperatures. Following the trend with $\mathrm{SiO}_{2}$, the replacement gate dielectric is expected to involve amorphous metal oxides to avoid surface roughness and additional leakage due to the formation of grain boundaries as expected in crystalline material. The higher atomic coordination numbers and ionic character of the metal oxides render them poor glass formers. ${ }^{16}$ Further, with increasing dielectric constant the crystallization temperature of the oxides also reduces due to increased ionicity, and even the recently preferred binary oxides (e.g., $\mathrm{HfO}_{2}$, $\mathrm{ZrO}_{2}$ ) do not withstand crystallization at typical CMOS processing temperatures. Alloying with $\mathrm{Si}$ or $\mathrm{Al}$ (i.e., silicates or aluminates) results in superior thermal stability and higher crystallization temperature, ${ }^{12,17-19}$ however, again at the expense of the highest achievable dielectric constant.

Based on the dielectric performance and process condition optimization, the first generation of high- $k$ dielectrics was expected to consist of Hf-based alloys. Interface engineering schemes have been developed to form oxynitride and oxide/nitride reaction barriers between these high- $k$ oxides and $\mathrm{Si}$ to minimize the reaction at the interface. ${ }^{20}$ The amorphous barrier layers used for $\mathrm{Si}$ surface passivation was not only promising for minimizing interfacial reaction but to maintain also high channel carrier mobility, which could otherwise be affected by the interfacial defects and the soft phonons of the high- $k$ oxides in direct contact with $\mathrm{Si}$. In 2007 Intel successfully demonstrated for the first time a $45 \mathrm{~nm}$ logic technology using Hf based high- $k$ metal gate stack transistors in a high volume manufacturing process, where an equivalent oxide thickness (EOT) of $\sim 1 \mathrm{~nm}$ was realized. ${ }^{21}$ This has gained wide adoption in the industry. ${ }^{6}$ While the integration of Hf based gate dielectric to the CMOS device process represented a remarkable success, it is obvious that the lowest possible EOT achievable using alternative dielectric material cannot be realized in presence of the interfacial layer due to their lower $k$ values.

Therefore, clearly further downscaling of CMOS devices must involve usage of high- $k$ oxide materials which should be integrated to $\mathrm{Si}$ without any interfacial layer to realize EOT $<0.8 \mathrm{~nm}$. Therefore, it is certainly not exaggeration to state that the quality of the interface between the high- $k$ oxide and $\mathrm{Si}$ will be the most important parameter to impact the device performance. A good interface quality can be expected either if the oxide is amorphous so that the number of Si dangling bonds at the interface can be minimized by local bonding adjustment, or if it is lattice matched to $\mathrm{Si}$ and grown epitaxial with atomically sharp interface. Epitaxial grown high- $k$ oxides could be a smart choice in this regard since this approach has the advantage of defined interface engineering and hence offers more control over the device properties despite larger process complexity related to the epitaxial growth process.

\section{EPITAXIAL GATE INSULATORS: CHOICE OF ALTERNATIVE METAL OXIDES}

In the recent past various epitaxial complex oxides, especially insulating binary rare earth oxides (REOs, mainly lanthanide oxides, LnOs), have drawn significant interest as prospective 2 nd generation of alternative gate dielectrics. ${ }^{22}$ Insulating LnOs form a very interesting group of materials for integration on $\mathrm{Si}^{4}$ as they offer several advantages, such as large dielectric constant, large band gap and band offsets to $\mathrm{Si}$, superior thermal and thermodynamic stabilities, which make them suitable for Si-based technologies. ${ }^{13,22}$ However, the choice of appropriate $\mathrm{LnOs}$ for gate dielectric application depends strongly on their stoichiometry. For example, some rare-earth metals exhibit multiple oxidation states $(+2,+3$, and +4$)$ which lead to oxides with different stoichiometry $\left(\mathrm{LnO}, \mathrm{Ln}_{2} \mathrm{O}_{3}, \mathrm{LnO}_{2}\right),{ }^{23}$ where not all the compositions are insulating. Moreover, the position of the charge neutrality level of ionic oxides depends strongly on their stoichiometry. ${ }^{24}$ Therefore, their band alignment to silicon and, finally, the leakage behavior becomes strongly dependent on the oxygen content. Therefore, LnOs which exhibit more than one stoichiometry (e.g., Ce-, Eu-oxides) or those which exhibits stable mixed valence structure (e.g., $\mathrm{Pr}_{6} \mathrm{O}_{11}$ ) are also not the best choices as alternative high- $k$ materials in Si-based devices. Consequently, for practical application it is wise to focus on those insulating LnOs in which the Ln metal possesses only a single valence state. Based on these criteria we focused mainly on LnOs containing $\mathrm{Ln}^{3+}$ cations (exhibiting the composition $\mathrm{Ln}_{2} \mathrm{O}_{3}$ ).

Additionally, $\mathrm{Ln}_{2} \mathrm{O}_{3}$ oxides can occur in different crystal structural phases (polymorphs) depending on temperature, e.g., cubic bixbyite structure $\left(\mathrm{Mn}_{2} \mathrm{O}_{3}\right.$ type), 
hexagonal lanthanum oxide structure $\left(\mathrm{La}_{2} \mathrm{O}_{3}\right.$ type $)$, and monoclinic structure $\left(\mathrm{Sm}_{2} \mathrm{O}_{3}\right.$ type $)$. The different structures exhibit different dielectric properties. Since temperaturedependent crystal phase transitions are not reversible or not completely reversible, and accompanied by interfacial layer formation on $\mathrm{Si}$, the controlled tuning of dielectric properties is difficult for $\mathrm{Ln}_{2} \mathrm{O}_{3} \mathrm{~s}$ which can undergo structural phase transformation already within a temperature range typical for CMOS processing ${ }^{25}$ which make them not suited for gate dielectric applications.

Based on these criteria we focus mainly on $\mathrm{Gd}_{2} \mathrm{O}_{3}$ (and to some extent on $\mathrm{Nd}_{2} \mathrm{O}_{3}$ ) for its epitaxial integration on $\mathrm{Si}$ as 2 nd generation alternative high- $k$ dielectric material. Bulk $\mathrm{Gd}_{2} \mathrm{O}_{3}$ occurs in the bixbyite cubic type of structure with single stoichiometry and structural transformation occurs only at $T>1400 \mathrm{~K} .^{26}$ In addition, this oxide has a large band gap of about $6 \mathrm{eV}$ and nearly symmetrical band offsets to $\mathrm{Si}^{27}$ a dielectric constant of 14 as well as a low lattice mismatch $(\sim 0.5 \%)$ with Si. The bixbyite structure of $\mathrm{Gd}_{2} \mathrm{O}_{3}$ has lattice symmetry suitable for epitaxial growth on $\mathrm{Si}(100)$ and $\mathrm{Si}(111)$. Although the lattice mismatch between $\mathrm{Gd}_{2} \mathrm{O}_{3}$ and $\mathrm{Si}$ are identical for $(100) / /(100),(110) / /(110)$, and $(111) / /(111)$ epitaxial arrangements based on the symmetry matching, it is to be noted that in practice $\mathrm{Gd}_{2} \mathrm{O}_{3}$ grows with (111) orientation on $\mathrm{Si}(111)$, whereas (110) oriented growth of $\mathrm{Gd}_{2} \mathrm{O}_{3}$ is observed on $\mathrm{Si}(100)$ surface under usual epitaxial growth conditions. A detailed discussion of the impact of symmetry matching and surface energy criteria on the epitaxial relation for $\mathrm{Gd}_{2} \mathrm{O}_{3}$ growth on $\mathrm{Si}(100)$ can be found elsewhere. ${ }^{22,28}$

\section{A. Epitaxial growth}

The epitaxial layers of $\mathrm{Gd}_{2} \mathrm{O}_{3}$ on different Si surfaces were grown by evaporating commercially available stoichiometric granular $\mathrm{Gd}_{2} \mathrm{O}_{3}$ using electron gun in a cluster solid source cluster molecular beam epitaxy system that includes a growth, an annealing, and an analytic chamber connected by an ultra-high vacuum (UHV) transfer system. The layers were grown on silicon substrates with different orientations. Substrates were cleaned ex situ using the last step diluted HF etch followed by a dilution rinse, and then were immediately inserted into the vacuum system. Growth temperatures were in the range of 800-1000 K. Typical growth rates were $0.005-0.01 \mathrm{~nm} / \mathrm{s}$. For some growth experiments, additional molecular oxygen was inserted in the chamber without any activation to yield an oxygen partial pressure $\left(P_{\mathrm{O}_{2}}\right)$ in the range of $10^{-7}$ mbar. For the fabrication of metal electrodes, the wafers were transferred immediately after the growth in vacuo into another chamber, where metal dots were evaporated through a shadow mask using electron beam heating. The surface and layer structure was evaluated during the growth by reflection high-energy electron diffraction (RHEED). The chemical natures of the oxides and the band alignment with $\mathrm{Si}$ have been investigated using in situ X-ray photoelectron spectroscopy (XPS) in a separate chamber without exposing the layers to atmosphere. Ex situ, the layers were characterized by X-ray diffraction (XRD) $(\theta / 2 \theta, \omega$ and $\Phi$-scans), by X-ray reflectivity for layer thickness determination (XRR) and by transmission electron microscopy (TEM). Figure 2 shows the X-ray $\left(\theta-2 \theta\right.$ scan) diffraction patterns of $\mathrm{Gd}_{2} \mathrm{O}_{3}$ thin films grown on different $\mathrm{Si}$ substrates. The scan for $\mathrm{Gd}_{2} \mathrm{O}_{3}$ layer on $\mathrm{Si}(001)$ surface exhibits a distinct peak at $2 \theta=46.4^{\circ}$ corresponding to the $d(440)$ inter planar spacing of cubic $\mathrm{Gd}_{2} \mathrm{O}_{3}$ along [110] orientation. The layers on the $\mathrm{Si}(111)$ substrate also exhibit single orientation without any indication of disoriented crystallites. The peaks at $28.5^{\circ}$ and $59.4^{\circ}$ corresponding to $d(222)$ and $d(444)$ interplanar spacing are hidden under the appropriate Si peaks. The scan for $\mathrm{Gd}_{2} \mathrm{O}_{3}$ thin films grown on $\mathrm{Si}(110)$ displays a peak at $28.5^{\circ}$ confirming the preferential growth along (111) direction.

\section{DEFECTS IN EPITAXIAL HIGH-k RARE EARTH OXIDES: SELECTING OPTIMUM GROWTH CONDITION}

The existence of various defects inside the layer and/or at the oxide/Si interface often degrades the device performance. Therefore, it is of paramount importance to understand the nature of the defects inside the metaloxide stack and at the oxide/Si interface and address their effective passivation for successful integration of epitaxial LnOs to typical CMOS technology.

Defects in the epitaxial LnOs can be broadly classified into two categories, e.g., structural defects and charge defects. The structural defects include domain boundary, misfit dislocation, stacking faults etc., whereas the charge defect encompasses oxide fixed charge, mobile oxide charges, and interface traps. In the present article we shall

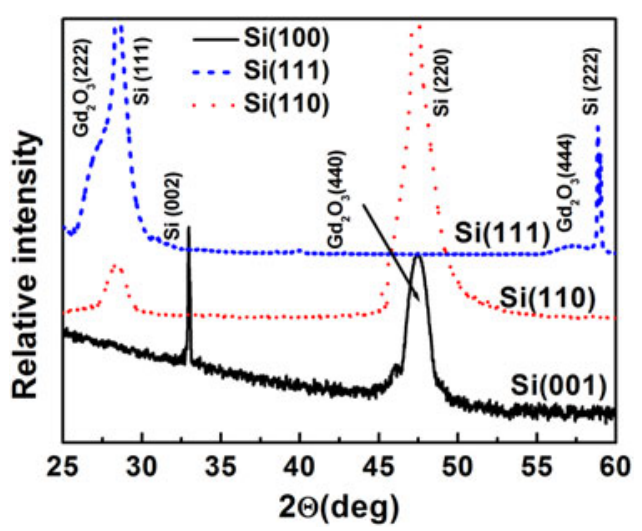

FIG. 2. X-ray diffraction patterns of $\mathrm{Gd}_{2} \mathrm{O}_{3}$ thin films grown on $\mathrm{Si}$ substrates with different orientation. 
focus mainly on the charge defects normally encountered in the epitaxial LnOs, their effect on the electrical properties of these heterostructures, and their effective passivation. It should be noted that to understand the role of the charge defects in the LnO thin films it is necessary to realize good structural quality of the epitaxial layers and atomically sharp interfaces with $\mathrm{Si}$. This is because in addition to the charge defects, the quality of interface between the oxide layer and Si surface also significantly influences the dielectric properties of the heterostructures. As a case study to understand the interface formation between the lanthanide oxides and $\mathrm{Si}$, Fissel et al. reported a detailed investigation of the interface formation between $\mathrm{Nd}_{2} \mathrm{O}_{3}$ and $\mathrm{Si}(100)$ during epitaxial growth. ${ }^{29}$ The RHEED investigation during MBE growth under UHV condition $\left(P_{\mathrm{O}_{2}}<5 \times 10^{-8}\right.$ mbar $)$ revealed that during the initial stage of oxide layer deposition the surface reconstruction of $\mathrm{Si}(100)$ changes from usual $(2 \times 1)$ of a clean surface to an unreconstructed $(1 \times 1)$. Further deposition leads to additional fractional order RHEED spots appearing at the $1 / 3$ positions between the main $(0,1)$ spots of the zero order Laue zone corresponding to a 3-fold surface periodicity at the surface [Fig. 3(a)]. Similar observation was already reported for the epitaxial growth of $\mathrm{Pr}_{2} \mathrm{O}_{3}$ on $\mathrm{Si}(001) .{ }^{30}$ During subsequent deposition, the surface changes back to the $(1 \times 1)$ structure before bulk spots appear related to diffraction from oxide islands [Fig. 3(b)]. The double spots in Fig. 3(b) correspond to two in-plane lattice constants nearly equal to the lattice constant of silicon and $\sqrt{ } 2$ times of that constant, respectively. This indicates that similar to other LnOs crystalline $\mathrm{Nd}_{2} \mathrm{O}_{3}$ grows in (110)-oriented domains, with orthogonal in-plane orientations. ${ }^{22,31}$ This is also evident from the X-ray diffraction pattern in the $\theta-2 \theta$ geometry, where only the (440) diffraction peak from the oxide layer is visible for the growth on $\mathrm{Si}(100)$ (Fig. 4).

The $\mathrm{Nd}_{2} \mathrm{O}_{3} / \mathrm{Si}$ interface formation was investigated in situ by XPS at different stages of the oxide layer growth. For layers with a thickness in the range up to $1 \mathrm{~nm}$, where the 3-fold periodicity in RHEED was found, the Si $2 p$ core level binding energy mainly corresponds to elemental $\mathrm{Si}\left(\mathrm{Si}^{0}\right.$ state) (Fig. 5). However, additionally a significant broadening was observed also toward the low-energy side of the $\mathrm{Si}^{0}$ peak. Deconvolution of the spectra by Gaussian fit indicated that for layers with thickness $\leq 1 \mathrm{~nm}$ the broadening can be explained by the additional occurrence of a $\mathrm{Si}^{1-}$ bonding state due to the formation of $\mathrm{Si}-\mathrm{Nd}$ bonds in the initial stage of growth. The relatively small shift in the peak position indicates the well-known $\mathrm{NdSi}_{2}$ phase formation. ${ }^{32}$ This finding agrees to an earlier report by Norton et al., where the formation of silicide like surface structure was also associated with the appearance of additional 1/3-order reflections on a $(2 \times 1)$ reconstructed surface during $\mathrm{Sr}$ deposition on $\mathrm{Si}(100) .{ }^{33}$ With increase in the $\mathrm{Nd}_{2} \mathrm{O}_{3}$ layer thickness of above $1 \mathrm{~nm}$ the spectra exhibit additional peaks at higher binding energies which could be attributed to the different kinds of silicate like bonds. ${ }^{34}$ The corresponding

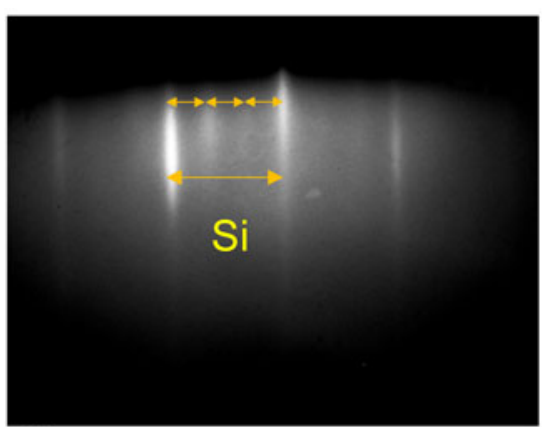

(a)

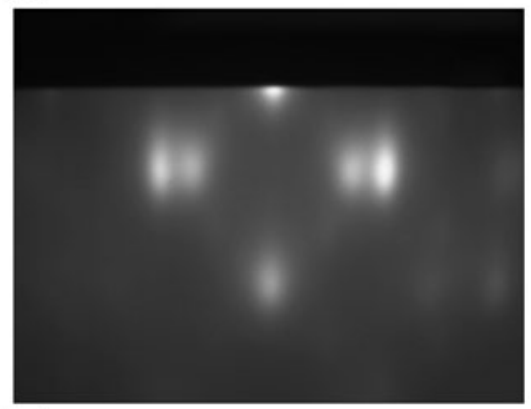

(b)

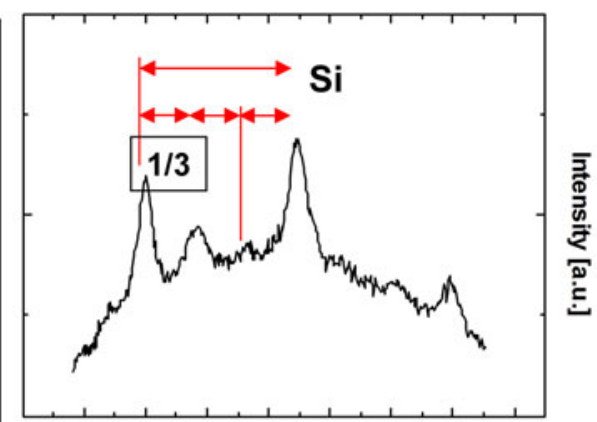

Distance [a.u.]

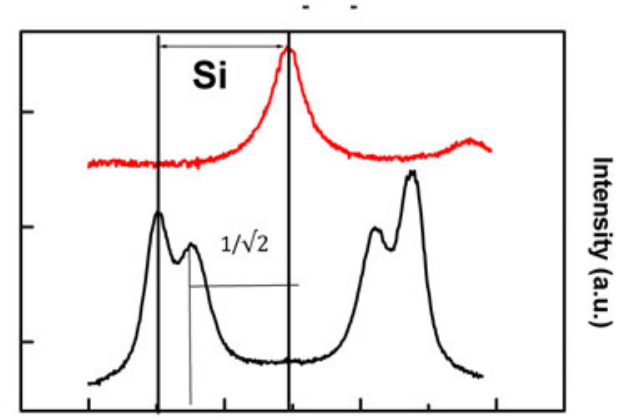

Distance (a.u.)

FIG. 3. RHEED pattern corresponding to $\mathrm{Nd}_{2} \mathrm{O}_{3}$ layer on a $\mathrm{Si}(100)$ wafer (a) $0.5 \mathrm{~nm} \mathrm{Nd} \mathrm{O}_{3}$ and (b) $2 \mathrm{~nm} \mathrm{Nd}_{2} \mathrm{O}_{3}$ layer thickness. The right hand side displays the intensity profiles along the marked line across the RHEED patterns. 


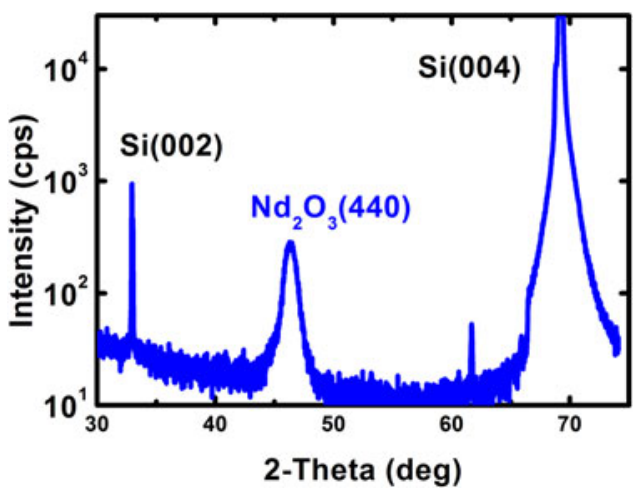

FIG. 4. X-ray diffraction pattern in the $\theta-2 \theta$ geometry of a $12 \mathrm{~nm}$ $\mathrm{Nd}_{2} \mathrm{O}_{3}$ layer grown on a $\mathrm{Si}(001)$ substrate.

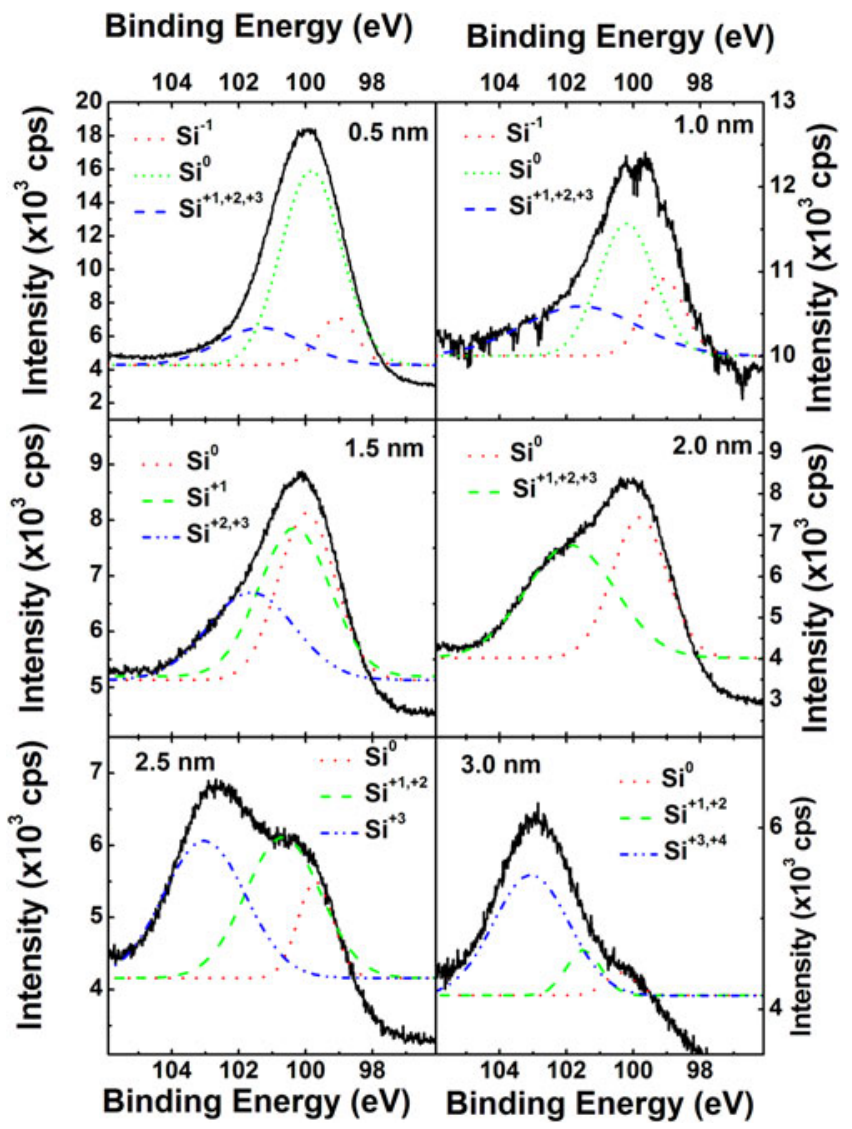

FIG. 5. Si $2 p$ spectra together with the appropriate multi peak fitting results of a $\mathrm{Si}$ wafer at different stages of $\mathrm{Nd}_{2} \mathrm{O}_{3}$ layer growth.

neodymium $3 d_{5 / 2}$ core-level spectra also supports the silicide-like bond formation at the interface during initial stage of the oxide layer growth (Fig. 6). For the second layer, a shift toward lower binding energies is observed which can be expected if the bonds become metal-like. That behavior together with the observed shifts in the $\mathrm{Si}$ spectra can only be explained by an exchange of oxygen bound to silicon by neodymium or by a movement of

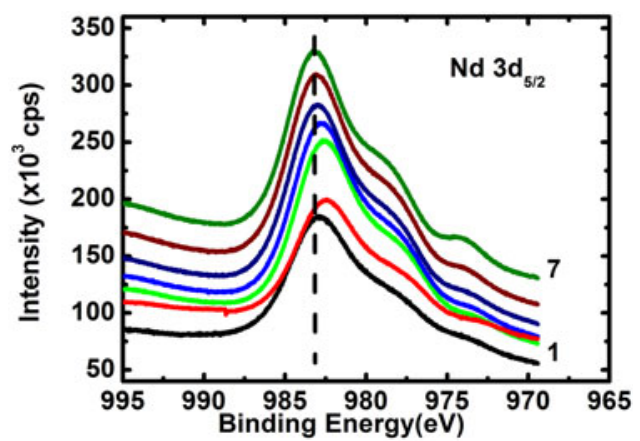

FIG. 6. $\mathrm{Nd} 3 d_{5 / 2}$ core-level XPS spectra for $\mathrm{Nd}_{2} \mathrm{O}_{3}$ layers of various thicknesses ranging between $0.5 \mathrm{~nm}$ (Spectra 1) to $3 \mathrm{~nm}$ (spectra 7). The dashed line represents the expected peak position for bulk $\mathrm{Nd}_{2} \mathrm{O}_{3}$.

oxygen atoms from a $\mathrm{Si}-\mathrm{O}-\mathrm{Nd}$ interface site into the layer during the initial stage of growth. TEM investigations also support this assumption. Figure 7 shows TEM micrographs of an $\mathrm{Nd}_{2} \mathrm{O}_{3} / \mathrm{Si}(001)$ heterostructure grown under UHV conditions. The plan-view micrograph exhibits typical Moire fringes originating from interfacial inclusions [Fig. 7(a)]. The crystalline inclusion with the interface extending some nanometers into the $\mathrm{Si}$ substrates is clearly seen in the cross-sectional micrographs [Fig. 7(b)]. Additionally, voids were also found in such layers. Based on a detailed analysis of the TEM results, the crystallographic structure of these inclusions could be identified to be identical to the known structure of tetragonal $\mathrm{NdSi}_{2} .{ }^{35}$ Other LnOs deposited on Si under identical growth condition exhibits similar results. For LnOs growth, the formation and stability of the silicidelike phase depend on the oxygen chemical potential. ${ }^{36}$ Considering the low $P_{\mathrm{O}_{2}}$ under UHV conditions (used in standard MBE growth), the chemical potential of oxygen can also become negative which can facilitate silicide formation over oxide formation. The silicide growth can continue as long as the oxygen chemical potential remains strongly negative due to low oxygen content. This effect predominates at a surface or interface region where the thermodynamic equilibrium is perturbed by different factors, such as stress.

However, such silicide inclusion at the $\mathrm{Ln}_{2} \mathrm{O}_{3} / \mathrm{Si}$ interface can potentially degrade their dielectric properties, especially in case of thin layers. Therefore, for high- $k$ dielectric application the interfacial silicide inclusion has to be avoided. One possible means to circumvent the silicide inclusions is annealing the deposited layers in an oxygen-rich atmosphere. However, such post deposition annealing normally gives rise to an amorphous interfacial layer. Fissel et al. reported that such interfacial layer consists of two regions (Fig. 8), one with lighter and one with darker contrast which was attributed to two different silicates. $^{29}$

These results indicate that to achieve a smooth interface between the epitaxial $\mathrm{Ln}_{2} \mathrm{O}_{3}$ and $\mathrm{Si}$, further growth 


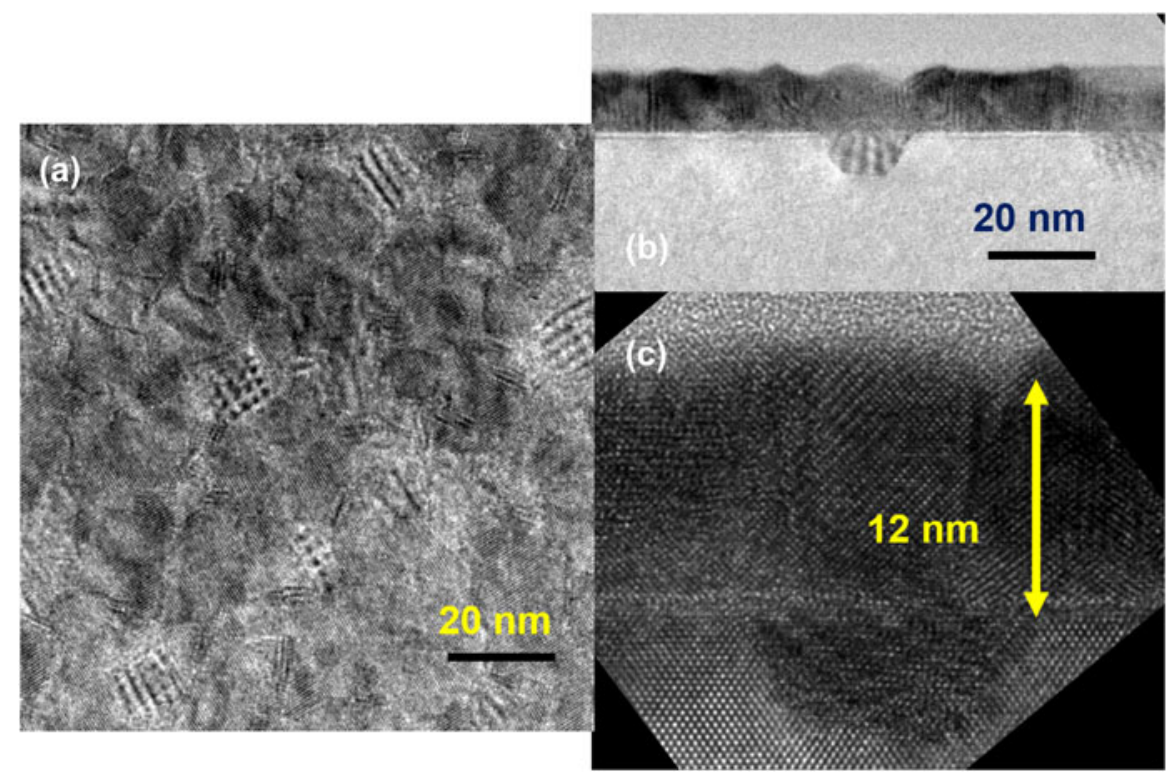

FIG. 7. TEM images of a $\mathrm{Nd}_{2} \mathrm{O}_{3}$ layer grown on $\mathrm{Si}(001)$, (a) plane-view micrograph, exhibiting pronounced Moiré fringes and (b, c) cross-sectional micrographs with different magnifications exhibiting the formation of crystalline interfacial inclusions. The two $\mathrm{Nd}_{2} \mathrm{O}_{3}(110)$ domains are indicated by white lines parallel to the atomic planes.

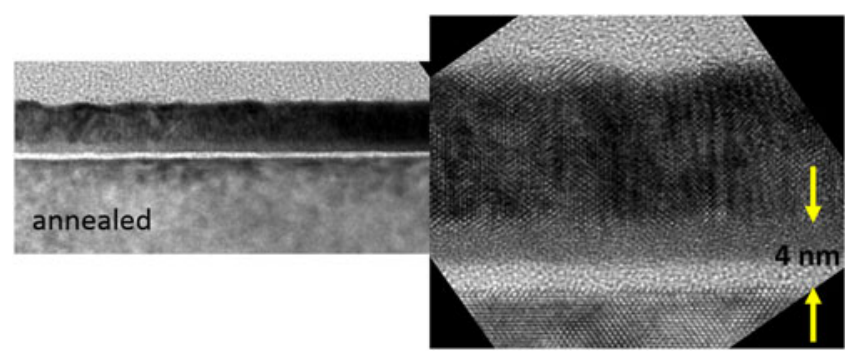

FIG. 8. Cross-sectional TEM micrograph of the $\mathrm{Nd}_{2} \mathrm{O}_{3}$ layer shown in Fig. 7, after annealing in nitrogen at a pressure of $2 \times 10^{-2} \mathrm{mbar}$, and temperature if $600{ }^{\circ} \mathrm{C}$ for $10 \mathrm{~min}$. In addition to the disappearance of the silicide inclusions, formation of an amorphous interfacial layer is visible.

engineering is necessary. In this view, a simple approach is to vary systematically the oxygen chemical potential by variation of the $P_{\mathrm{O}_{2}}$ during oxide layer. This has been demonstrated by Czernohorsky et al., where a modified MBE growth process was developed in which the chemical potential of oxygen was optimized with respect to the electrical properties by introducing additional nonactivated molecular oxygen during growth to keep the partial pressure in the range of $10^{-7}$ mbar. $^{37}$ This was found to result in a sharp interface between $\mathrm{Gd}_{2} \mathrm{O}_{3}$ and $\mathrm{Si}$ (Fig. 9), free from any silicide inclusions as well as silicate or silicon oxide. Therefore, such layers are ideal candidates for investigating the manifestation of charge defects and their influence on the dielectric properties of epitaxial $\mathrm{Ln}_{2} \mathrm{O}_{3}$ s.

Preliminary investigation of electrical properties of epitaxial layers grown under optimized conditions exhibited very promising characteristics, such as low capacitive equivalent thickness and low leakage current density (CET $<1 \mathrm{~nm}, J \approx 10^{-1} \mathrm{~A} / \mathrm{cm}^{2}$ ). Gottlob et al. reported CET $\sim 0.86 \mathrm{~nm}$ and a leakage current density of $\sim 0.5 \mathrm{~A} . \mathrm{cm}^{-2}$ at $1 \mathrm{~V}$ gate bias for MOS stacks consisting of ultra-thin $\mathrm{Gd}_{2} \mathrm{O}_{3}$ layers with CMOS-compatible fully silicided nickel-silicide (FUSI-NiSi) metal gate electrodes yields. ${ }^{38}$ The CET trend observed for the MOS structures with $\mathrm{Gd}_{2} \mathrm{O}_{3}$ gate dielectric and FUSI-NiSi electrode combination met all ITRS targets for oxide thickness as well as leakage current values for high performance (HP), low operating power (LOP), and low standby power (LSTP) applications (Fig. 10). The reported CET values (without quantum-mechanical corrections) represent an upper limit of the achieved effective oxide thickness (EOT). Assuming a quantummechanical correction of $0.3 \mathrm{~nm}$ to obtain EOT values shifts the trend line to an even more desirable region of specifications. ${ }^{6}$ These results indicated that $\mathrm{NiSi} / \mathrm{Gd}_{2} \mathrm{O}_{3}$ gate stacks with optimized oxide/Si interface properties could be quite promising candidates for scaling efforts to the limit of CMOS. However, despite the outstanding structural qualities, compatibility with CMOS process techniques including metal gate incorporation and encouraging electrical properties the epitaxial $\mathrm{Gd}_{2} \mathrm{O}_{3}$ layers (or for that matter other insulating $\mathrm{Ln}_{2} \mathrm{O}_{3} \mathrm{~s}$ ) suffer from several performance related issues which are required to be addressed prior to real device integration. For example, the MOS structure exhibiting EOT $\sim 0.86 \mathrm{~nm}$ shows strong hysteresis $(\sim 120 \mathrm{mV})$ in the capacitancevoltage $(C-V)$ profile when the gate bias between forward and backward sweeps at $500 \mathrm{kHz}$. The hysteretic feature of the $C-V$ profile indicates presence of charge defects inside 


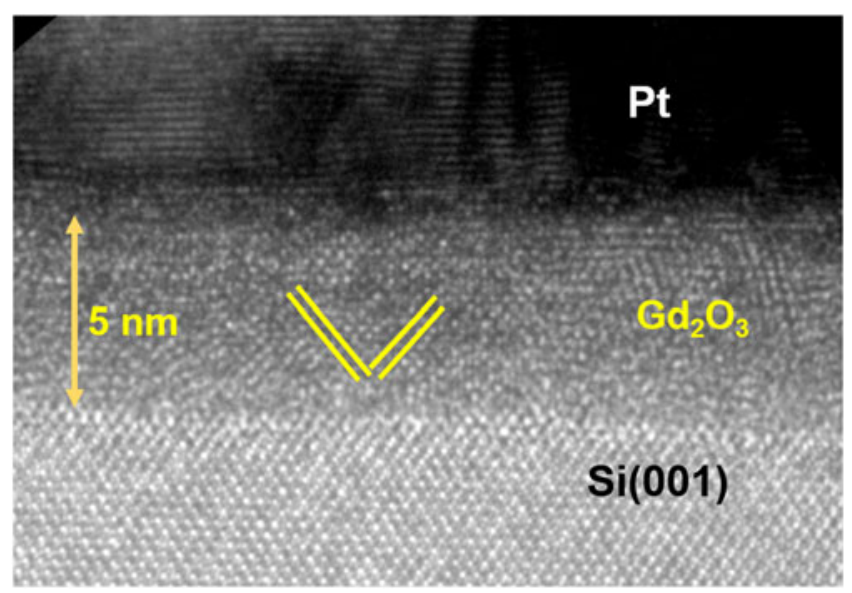

FIG. 9. High-resolution cross-sectional TEM micrograph of a $\mathrm{Pt} / \mathrm{Gd}_{2} \mathrm{O}_{3} / \mathrm{Si}(001)$ stack. The oxide layer is grown at under a molecular oxygen partial pressure of $5 \times 10^{-7}$ mbar. Sharp interface without any amorphous interfacial layer is visible.

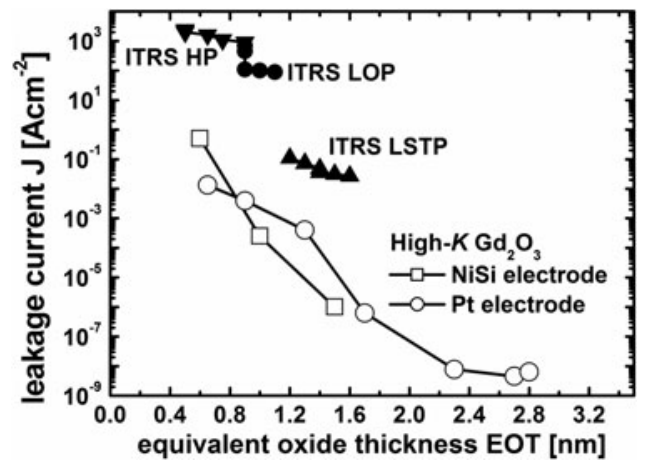

FIG. 10. Leakage currents versus EOT for ITRS (edition 2005) HP, LOP, LSTP target values, and data epitaxial $\mathrm{Gd}_{2} \mathrm{O}_{3}$ layers with different electrodes.

the oxide layer and/or oxide/Si interface. Gottlob et al. attributed this to oxide traps $\left(Q_{\mathrm{ot}}=3 \times 10^{12} \mathrm{~cm}^{-2}\right){ }^{38}$ Such hysteresis represents flat band voltage $\left(V_{\mathrm{FB}}\right)$ instability of the dielectric layer which leads to unstable threshold voltage in transistors. This clearly establishes that excellent structural quality of the alternative high- $k$ dielectric does not guarantee satisfactory device performance due to the presence of electrically active charge defects.

\section{A. Charge defects in epitaxial lanthanide oxides}

In MOS structures there can be different types of charge defects that can degrade their electrical performance, such as oxide fixed charge $\left(Q_{\mathrm{f}}\right)$, interface traps $\left(Q_{\mathrm{it}}\right)$, and mobile oxide charges $\left(Q_{\mathrm{m}}\right)$. In addition to unstable threshold voltage and instability of transistor operating characteristics, charge defects scatters carriers in the channel and lowers the carrier mobility. Further, defects cause unreliability; which is the starting point for electrical failure and breakdown of the oxide. $\mathrm{SiO}_{2}$, which is an almost ideal insulating oxide, has very low defect density. The low co-ordination number and high heat of formation of covalent $\mathrm{SiO}_{2}$, that allow it to remain amorphous at typical CMOS processing temperature, helps to minimize the defect density via localized bonding rearrangement. Further, the defects at the $\mathrm{Si} / \mathrm{SiO}_{2}$ interface related to $\mathrm{Si}$ dangling bonds can be removed by rearranging the bonding network at the interface. Compared to $\mathrm{SiO}_{2}$, high- $k$ metal oxides normally contain more defects. The bonding in high- $k$ metal oxides is highly ionic with higher coordination number which make them poor glass formers. ${ }^{16}$ Therefore, it is difficult to rearrange the bonds in the metal oxides for defect passivation. Since the charge defects in high- $k$ dielectrics are undesirable for device applications for obvious reasons, much of the present-day engineering of these oxides consists of pragmatic strategies of trying to reduce defect densities by processing control and annealing. In this section we discuss about the nature of different charge defects existing in epitaxial $\mathrm{LnOs}$ and at the $\mathrm{Ln}_{2} \mathrm{O}_{3} / \mathrm{Si}$ interface and their effective passivation to improve the dielectric performance.

Let us start with the issues related to the dielectric properties of as-grown epitaxial $\mathrm{Gd}_{2} \mathrm{O}_{3}$ layers. The as-grown single crystalline $\mathrm{Gd}_{2} \mathrm{O}_{3}$ thin films on Si usually suffer from strong flatband voltage $\left(V_{\mathrm{FB}}\right)$ instability and are not process robust. This could be due to incomplete passivation of intrinsic dangling bonds induced by the existing binding mismatch at the $\mathrm{Gd}_{2} \mathrm{O}_{3} / \mathrm{Si}$ interface. When a $\mathrm{Gd}_{2} \mathrm{O}_{3}$ layer is deposited on clean $\mathrm{Si}$ surface; inevitably, the layer always consists of some defects pertaining to the Si dangling bonds at the interface and also due to the very different chemical nature of $\mathrm{Si}$ substrate (covalent) and oxide (highly ionic). Despite the oxide being grown epitaxially on Si substrate, not all $\mathrm{Si}$ surface atoms would have an opportunity to bond with overgrown epi- $\mathrm{Gd}_{2} \mathrm{O}_{3}$ layer's atoms. Such defects remain unsaturated due to the difference in the lattice parameters and space groups of the oxide and $\mathrm{Si}$ substrate. $^{34}$

For example, MOS structures consisting of epitaxial $\mathrm{Gd}_{2} \mathrm{O}_{3}$ grown on clean $\mathrm{Si}$ substrates with atomically sharp interface, exhibit a large shift in the flat band voltage toward negative gate bias direction during multiple $C-V$ sweeping (Fig. 11), which infers to a large number of intrinsic/extrinsic defects present at the interface. ${ }^{39}$ Such instability occurs due to the accumulation of mostly positive fixed charges at the $\mathrm{Gd}_{2} \mathrm{O}_{3} / \mathrm{Si}$ interface created during $C-V$ sweeping, ${ }^{39,40}$ which could significantly degrade the electrical performance of any device. ${ }^{41,42}$ Laha et al. reported $Q_{\mathrm{f}} \sim 9.5 \times 10^{12} \mathrm{~cm}^{-2}$ for epitaxial $\mathrm{Gd}_{2} \mathrm{O}_{3}$ on $\mathrm{Si}$ which is only two orders of magnitude lower than the atomic density of dangling bonds on 


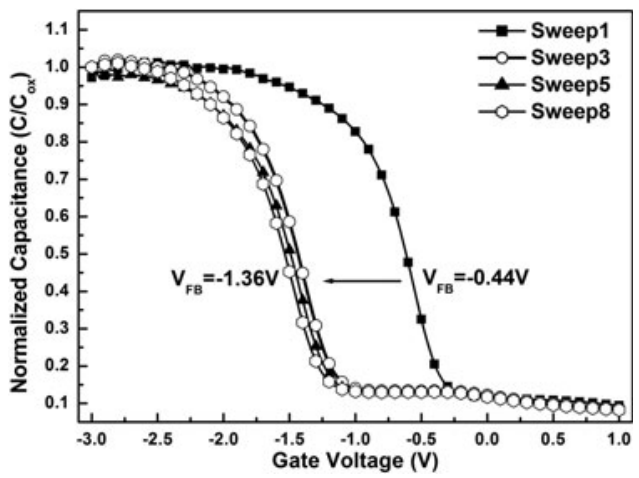

FIG. 11. $C-V$ characteristics of single crystalline $\mathrm{Gd}_{2} \mathrm{O}_{3}$ on $\mathrm{Si}(100)$ substrate.

a nonreconstructed $\mathrm{Si}(001)$ surface. This implies that approximately $1 \%$ of $\mathrm{Si}$ surface bonds remain unsaturated even after oxide growth onto it. ${ }^{40}$ Each Si surface atom possessing a dangling bond usually seeks an additional electron to become electrically neutral. They tend to capture the required electrons from the oxide layer near the interface, thereby creating large number electron vacancies, i.e., positive charges, which results in a large shift of the flat band voltage.

In addition to the shift in the $V_{\mathrm{FB}}$ under applied bias, MOS structures involving epitaxial $\mathrm{Gd}_{2} \mathrm{O}_{3}$ layers on $\mathrm{Si}$ also suffer from significant $C-V$ hysteresis when the gate bias is cycled from accumulation to the inversion region and back. This hysteretic nature of the $C-V$ characteristic is related to some sort of recharging process inside the dielectric. The origin of the observed hysteresis may not be unambiguously associated with some definite process. Nazarov et al. suggested that the $C-V$ hysteresis in epitaxial $\mathrm{Gd}_{2} \mathrm{O}_{3} / \mathrm{Si}$ system could be attributed to both trapping of the holes inside the dielectric and recharging the electrons near-surface traps. ${ }^{43}$ One of the major sources of charge trapping in the metal oxides is the omnipresent oxygen vacancies $\left(\mathrm{V}_{\mathrm{O}} \mathrm{s}\right)$ inside the layer, which give rise to defect states inside the band gap of the metal oxides. $V_{O}$ s have been identified as critical trapping centers in diverse high- $k$ metal oxides, such as $\mathrm{HfO}_{2}, \mathrm{ZrO}_{2}, \mathrm{LaAlO}_{3}$ etc. ${ }^{44,45}$ Further, in ionic metal oxides $\mathrm{V}_{\mathrm{O}} \mathrm{s}$ redistribution can also occur under sufficiently high electric field, ${ }^{46,47}$ which can act as potential source of $Q_{\mathrm{m}}$, thereby contributing at least partially to the observed $C-V$ hysteresis. Czernohorsky et al. demonstrated that the hysteretic $C-V$ characteristics of $\mathrm{Gd}_{2} \mathrm{O}_{3} / \mathrm{Si}$ heterostructures varies with $P_{\mathrm{O}_{2}}$ up to a certain limit, which clearly establishes the definitive role of $\mathrm{V}_{\mathrm{O}} \mathrm{S}$ on the hysteretic $V_{\mathrm{FB}}$ instability of epitaxial $\mathrm{Gd}_{2} \mathrm{O}_{3}$ layers. ${ }^{37}$ It is obvious that such charge defects, which degrade the dielectric properties of epitaxial $\mathrm{Ln}_{2} \mathrm{O}_{3}$ s, need to be minimized to improve their electrical performance prior to their integration into microelectronic devices.

\section{PASSIVATION OF THE CHARGE DEFECTS IN EPITAXIAL LANTHANIDE OXIDES}

In semiconductor industry one of the most commonly practiced method for passivation of charge defects in MOS structures is a thermal anneal in forming gas ambience. As a first measure for passivation of interface defect states in epitaxial $\mathrm{Ln}_{2} \mathrm{O}_{3} \mathrm{~s} / \mathrm{Si}$ heterostructures Sun et al. investigated forming gas anneal for the $\mathrm{Gd}_{2} \mathrm{O}_{3} / \mathrm{Si}$ system and found an influence of metal electrode. ${ }^{39}$ For example, a post MOS fabrication anneal was found to be effective in case of tungsten electrode, whereas annealing prior to the electrode deposition was found necessary for Pt electrodes. Annealing epitaxial $\mathrm{Gd}_{2} \mathrm{O}_{3} / \mathrm{Si}$ system in forming gas environment at around $450{ }^{\circ} \mathrm{C}$ has been reported to reduce the $Q_{\mathrm{f}} \mathrm{s}$ which stabilizes the $V_{\mathrm{FB}}$. However, this approach is not only very specific to the electrode type, but is not effective for complete elimination of $Q_{\mathrm{f}} \mathrm{s}$ in the epitaxial $\mathrm{Ln}_{2} \mathrm{O}_{3} \mathrm{~s}$. A negative shift in the flat band voltage $(\sim-0.44 \mathrm{~V})$ for $\mathrm{Pt} / \mathrm{Gd}_{2} \mathrm{O}_{3} / \mathrm{Si}$ stack has been reported even after the forming gas anneal of the MOS structures fabricated on p-type Si. The negative flat band voltage results from $Q_{\mathrm{f}} \approx 2.3 \times 10^{12} / \mathrm{cm}^{2}$, which is estimated using the relation: $Q_{\mathrm{f}}=C_{\mathrm{ox}}\left(V_{\mathrm{FB}}-\Phi_{\mathrm{ms}}\right)$, where $C_{\mathrm{ox}}$ is the oxide layer capacitance and $\Phi_{\mathrm{ms}}$ is the metal work function. Additionally, $\mathrm{Pt} / \mathrm{Gd}_{2} \mathrm{O}_{3} / \mathrm{Si}$ stacks possess a large density of trapped interface charges $\left(D_{\text {it }} \sim 7.63-8.8 \times 10^{11} \mathrm{~cm}^{-2}\right) .{ }^{39}$ These findings clearly indicate that forming gas anneal is an inadequate method to provide acceptable electrical properties for epitaxial $\mathrm{Ln}_{2} \mathrm{O}_{3}$ s. Moreover, post deposition anneal also involves the risk of creating uncontrolled interfacial layer, exhibiting smaller dielectric constant as well as results in loss of epitaxy. As an alternative to forming gas anneal, Laha et al. demonstrated that the electrical properties of $\mathrm{Gd}_{2} \mathrm{O}_{3} / \mathrm{Si}$ structures can be improved significantly by interface engineering that involves atomic control growth of a silicate-like interfacial structure prior to the $\mathrm{Gd}_{2} \mathrm{O}_{3}$ layer. ${ }^{48}$ However, controlling the interface composition is quite tedious and it involves multiple steps for substrate's surface preparation which renders the method less preferred for device fabrication. Another viable alternative surface preparation approach could be the passivation of Si dangling bond states by suitable chemisorbed species prior to the oxide layer growth. For examples, it has been widely reported that an ultrathin $\mathrm{Si}$ layer is very effective to passivate $\mathrm{Ge}$ surfaces for deep sub-micron p- and n-field effect transistor (FET) application, ${ }^{49-51}$ whereas similar investigation for the effect of $\mathrm{Ge}$ on $\mathrm{Si}$ based devices is not commonplace. But it can be expected that deposition of Ge onto Si surface has also significant impact on the surface charge states of $\mathrm{Si}$. It is known that a submonolayer (ML) Ge deposited onto a Si(111) surface leads to a charge transfer from the center $\mathrm{Si}$ adatoms 
near the faulted half unit cell (FHUC) of a $\mathrm{Si}(111)$ $(7 \times 7)$ unit cell to the nearby Ge atoms, which makes the dangling bond states of $\mathrm{Si}$ adatoms empty. ${ }^{52}$ In principle this effect might have significant impact on subsequent properties of devices built on such $\mathrm{Si}$ surfaces. Laha et al. investigated the influence of chemisorbed $\mathrm{Ge}$ layer on the growth and dielectric properties of epitaxial $\mathrm{Gd}_{2} \mathrm{O}_{3}$ layers on $\mathrm{Si}^{40}$ In this approach different amount of $\mathrm{Ge}(0.15-3 \mathrm{ML})$ was deposited by e-beam evaporation on clean $\mathrm{Si}$ surfaces prior to the $\mathrm{Gd}_{2} \mathrm{O}_{3}$ layer growth. The in situ RHEED patterns of the $\mathrm{Gd}_{2} \mathrm{O}_{3}$ layers grown on such Ge-covered $\mathrm{Si}$ surfaces (Fig. 12) are very similar to what has been observed for the layers grown pristine Si surfaces. ${ }^{53}$ This demonstrates that despite the large lattice mismatch between Si and Ge, few MLs of Ge pre-coverage $\left(\Phi_{\mathrm{Ge}}\right)$ does not have any impact on the growth and structure of the $\mathrm{Gd}_{2} \mathrm{O}_{3}$ layer for $\Phi_{\mathrm{Ge}}$ at least up to $2 \mathrm{ML}$. Figure 13 compares the $C-V$ characteristics of $\mathrm{Gd}_{2} \mathrm{O}_{3}$ layers grown on pristine $\mathrm{Si}$ surface and on a $\mathrm{Ge}$ pre-covered Si surface. A strong $V_{\mathrm{FB}}$ instability corresponding to $Q_{\mathrm{f}}$ $\sim 9.5 \times 10^{12} \mathrm{~cm}^{-2}$ was observed in case of $\mathrm{Gd}_{2} \mathrm{O}_{3}$ grown on $\mathrm{Si}$ surface without $\mathrm{Ge}$ passivation, whereas for $\mathrm{Si}$ passivated with $1.5 \mathrm{ML}$ Ge a much stable and ideal-like $C-V$ characteristics was obtained. A systematic increase in $\Phi_{\mathrm{Ge}}$ leads to a monotonic increase in $V_{\mathrm{FB}}$ up to a maximum value of $0.3 \mathrm{~V}$ for $1.5 \mathrm{ML}$ of Ge coverage [Fig. 14 (a)]. Further increase of Ge coverage was reported to result in nonuniformity in $C-V$ measurements across the wafer. $^{40}$ The estimated $V_{\mathrm{FB}}$ in this case $(+0.3 \mathrm{~V})$ indicates negligible amount $Q_{\mathrm{f}}$ present at the interface. This improvement in the dielectric properties of the $\mathrm{Gd}_{2} \mathrm{O}_{3}$ layers was found to be independent of the $\mathrm{Si}$ surface orientation. It was also found that Ge pre-coverage on $\mathrm{Si}$ surface improves the density of interface traps significantly [Fig. 14 (b)], which also led to significant reduction in the hysteresis of the $C-V$ characteristic. ${ }^{40}$ These results clearly indicate that $\mathrm{Ge}$ deposition prior to the oxide layer growth significantly influence the electronic properties of $\mathrm{Si}$ surfaces and, consequently, the oxide/Si interface. To understand the influence of $\mathrm{Ge}$ on the surface electronic properties, Laha et al. also investigated the $\mathrm{Si}(111)$ surface states with different $\Phi_{\mathrm{Ge}}$ using UPS. Figure 15 displays the photoemission spectra of $\mathrm{Si}(111)$ surfaces with different $\Phi_{\mathrm{Ge}}$. For pristine $\operatorname{Si}(111)-(7 \times 7)$ surfaces $\left(\Phi_{\mathrm{Ge}} \sim 0\right)$, the well-known signals related to the adatom state $\left(S_{1}\right)$, the rest atom state $\left(\mathrm{S}_{2}\right)$, and the back-bond state $\left(\mathrm{S}_{3}\right)$, are visible at energies close to the Fermi level $\left(E_{\mathrm{F}}\right) .{ }^{54,55}$ In contrast, the spectra from the Ge covered $\mathrm{Si}(111)$ surface exhibits only two surface states measured under the same condition, one $\left(\mathrm{B}_{1}\right)$ about $0.38 \mathrm{eV}$ and the other about $1.70 \mathrm{eV}\left(\mathrm{B}_{3}\right)$ below the Fermi level. The first peak corresponds to the adatom state of clean $\operatorname{Si}(111)-(7 \times 7)$ surface, whereas the energetic position of the second peak $\left(B_{3}\right)$ is located in between the $S_{2}$ and $S_{3}$ states of the clean $\mathrm{Si}$ surface. These results are in accordance to the earlier report by Carlisle et al., ${ }^{56}$ where it was found that with increasing $\Phi_{\mathrm{Ge}}(>0.3 \mathrm{ML})$, rest-atom and back-bond surface states merge into one broad feature located approximately halfway between them. ${ }^{57}$ Such changes in the surface states indicate significant change in the atomic arrangement of the $\mathrm{Si}$ surface due to $\mathrm{Ge}$ deposition. For example, in case of $\mathrm{Si}(111)$ the chemisorbed $\mathrm{Ge}$ atoms randomly occupy the $\mathrm{Si}$ adatom positions at the very early stage $\left(\Phi_{\mathrm{Ge}}<0.1 \mathrm{ML}\right)$. However, with increasing coverage they preferentially occupy the corner adatoms' position in the FHUC of Si $(111)(7 \times 7)$ surface structure. ${ }^{58,59}$ At higher coverage $\left(\Phi_{\mathrm{Ge}}>0.5 \mathrm{ML}\right), \mathrm{Ge}$ atoms form nanoparticles on FHUC side consisting of approximately eight atoms. ${ }^{52,60}$ In the presence of $\mathrm{Ge}$ nanoparticles, the $\mathrm{Si}$ center adatoms transfer charges to the nearby Ge atoms and thereby dangling bond states of such adatoms become partly empty. ${ }^{52}$ Such charge transfer from $\mathrm{Si}$ to Ge occurs due to the difference in electronegativity and the compressive strain in Ge layer. Consequently, dipoles form at the $\mathrm{Si} / \mathrm{Ge}$ interface with an excess of 0.1 electrons on the Ge side. ${ }^{61}$ Similar behavior has also been reported

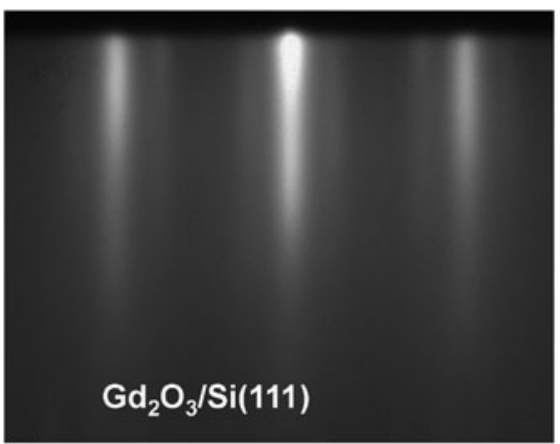

(a)

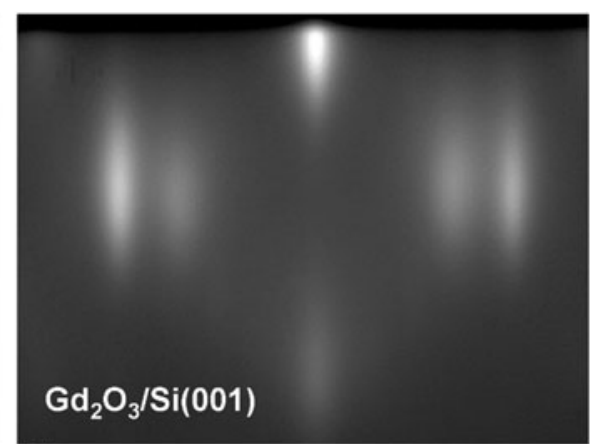

(b)

FIG. 12. RHEED patterns of epitaxial $\mathrm{Gd}_{2} \mathrm{O}_{3}$ on (a) $\mathrm{Si}(111)$ and (b) $\mathrm{Si}(001)$ substrates. 2 ML Ge was deposited on $\mathrm{Si}$ surface prior to the oxide layer growth. (Reprinted from Ref. 40 with permission of AIP publishing). 


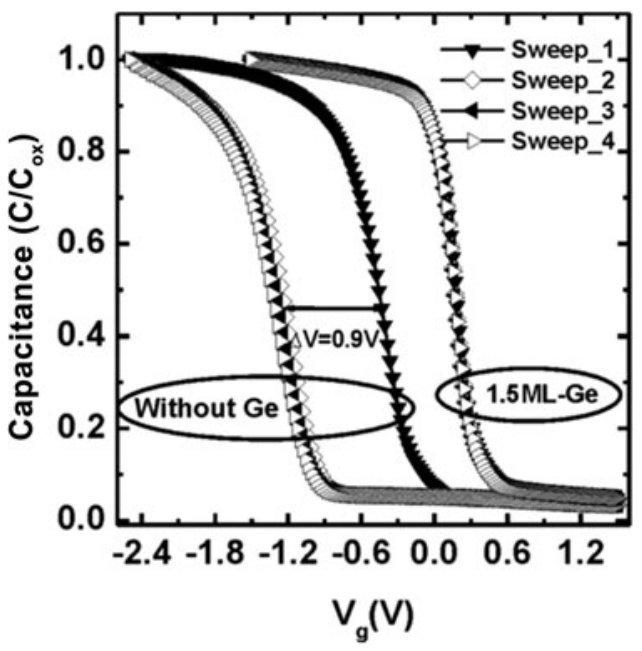

FIG. 13. $C-V$ characteristics of $\mathrm{Pt} / \mathrm{Gd}_{2} \mathrm{O}_{3} / \mathrm{Si}(001)$ MOS capacitors depicting the effect of $1.5 \mathrm{ML}$ Ge coverage on $\mathrm{Si}(001)$ substrates. The capacitors fabricated on $\mathrm{Ge}$ passivated $\mathrm{Si}$ surface exhibit improved $C-V$ behavior. (Reprinted from Ref. 40 with permission of AIP publishing).
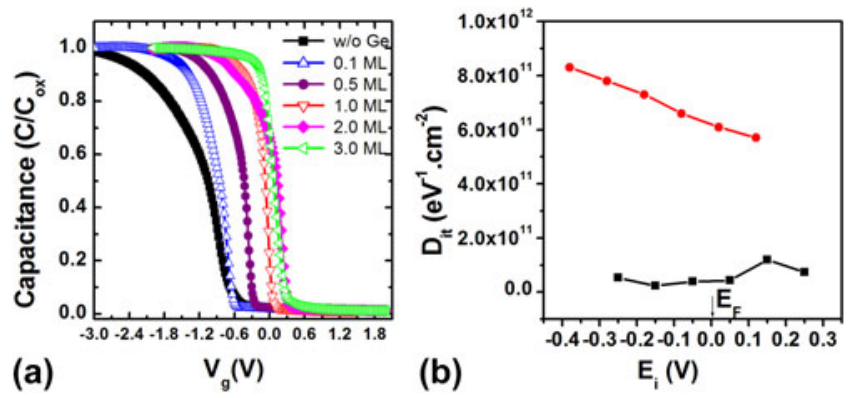

FIG. 14. (a) The $C-V$ characteristics of $\mathrm{Pt} / \mathrm{Gd}_{2} \mathrm{O}_{3} / \mathrm{Si}(111)$ MOS capacitors as a function of Ge coverage. The flat band voltage increases monotonically with increasing Ge coverage up to $\sim 1.5 \mathrm{ML}$. (b) Density of interface traps for $\mathrm{Pt} / \mathrm{Gd}_{2} \mathrm{O}_{3} / \mathrm{Si}$ capacitors fabricated on clean and $\mathrm{Ge}$ passivated $\mathrm{Si}(111)$ wafers, exhibiting significant improvement on $D_{\text {it }}$ values.

by various other groups for the $\mathrm{Si}(001)$ surfaces, ${ }^{62,63}$ despite their different microstructure. ${ }^{64}$

Therefore, the observed reduction in fixed oxide charge density in the $\mathrm{Gd}_{2} \mathrm{O}_{3} / \mathrm{Si}$ interface can mainly be attributed to the charge transfer from $\mathrm{Si}$ dangling bonds toward $\mathrm{Ge}$. In case of $\mathrm{Gd}_{2} \mathrm{O}_{3}$ growth on $\mathrm{Si}$ without predeposited $\mathrm{Ge}$ the remaining dangling bonds in the oxide/Si interface attempt to capture additional electrons from oxide regions close to the interface to become electrically neutral. Thereby, large number electron vacancies will be created, i.e., positive charges, which results in a large shift of $V_{\mathrm{FB}}$. In contrast, when epitaxial $\mathrm{Gd}_{2} \mathrm{O}_{3}$ is grown on a $\mathrm{Ge}$ passivated surface, the contribution of the adatom dangling bond states significantly decreases. Moreover, due to the higher electron density at the top Ge layer owing to dipole formation, it is very unlikely that the electrons from the oxide interface

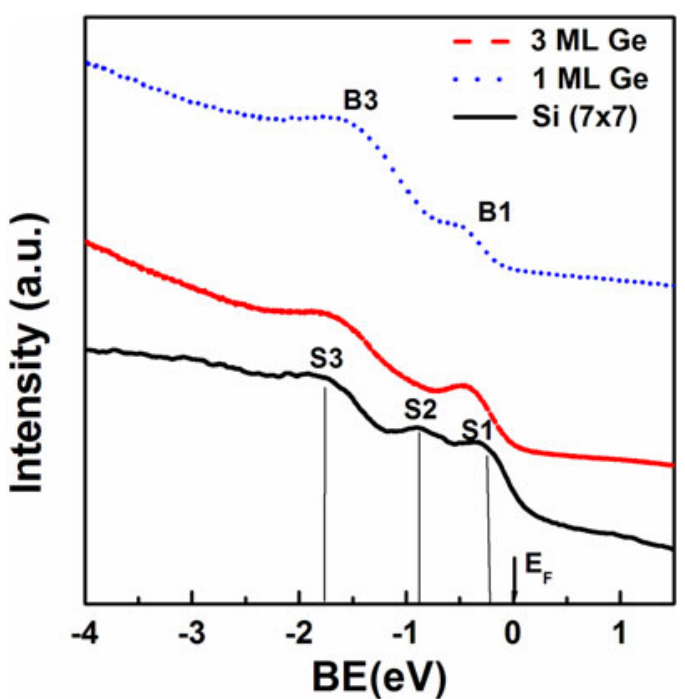

FIG. 15. UPS spectra from clean $\operatorname{Si}(111)(7 \times 7)$ surfaces with different $\mathrm{Ge}$ coverage, obtained at a photon energy of $21.2 \mathrm{eV}$. The spectra were recorded along $\langle 11-2\rangle$ azimuth at an emission angle of $5^{\circ}$ with respect to surface normal.

would be captured by the underlying substrates, which leads to much more stable interface.

A reduction in fixed oxide charge density in the $\mathrm{Gd}_{2} \mathrm{O}_{3} / \mathrm{Si}$ interface and resultant improvement in the $V_{\mathrm{FB}}$ stability of epitaxial $\mathrm{Gd}_{2} \mathrm{O}_{3} / \mathrm{Si}$ structures was observed also for oxide layers grown on $\mathrm{Si}$ covered by submonolayer carbon, ${ }^{65}$ indicating a similar charge transfer effect. Moreover, it was established that $V_{\mathrm{FB}}$ can be tailored by tuning the concentration of the chemisorbed species which can provide additional flexibility for device operation. ${ }^{40,65,66}$ These observations establish the proof of principle about defect minimization at the oxide/Si interface by $\mathrm{Si}$ dangling bond passivation via charge transfer from $\mathrm{Si}$ adatoms to isovalent chemisorbed species with higher electronegativity.

Although surface passivation of $\mathrm{Si}$ by isoelectronic elements (Ge or $\mathrm{C}$ ) prior to the oxide layer growth is a simple and effective way to reduce the fixed oxide charge and trap densities at the epitaxial $\mathrm{Gd}_{2} \mathrm{O}_{3} / \mathrm{Si}$ interface, this cannot completely eliminate the hysteretic $C-V$ characteristics of the MOS structures. As discussed in the previous section, in addition to charging effect, the hysteresis in $C-V$ could be partially related to the mobile charge defects inside the oxide layer owing to $\mathrm{V}_{\mathrm{O}}$ s. Earlier we observed that with an increase in oxygen chemical potential during the oxide layer growth by an increase in $P_{\mathrm{O}_{2}}$ from $1 \times 10^{7}$ mbar to $5 \times 10^{7}$ mbar, the hysteresis also reduces significantly (Fig. 16). ${ }^{37}$ However, a monotonic increase in $P_{\mathrm{O}_{2}}$ does not ensure complete elimination of the $\mathrm{V}_{\mathrm{O}} \mathrm{S}$ in the oxide layers. ${ }^{37}$ Moreover, the magnitude of the flatband voltage change from voltage cycling $\left(\Delta V_{\mathrm{FB}}>40 \mathrm{mV}\right)$ was still beyond the acceptable value $\left(\Delta V_{\mathrm{FB}}<20 \mathrm{mV}\right)$ for stable transistor operation. ${ }^{12}$ 
Therefore, to minimize the $\mathrm{V}_{\mathrm{O}} \mathrm{S}$ related defects various post growth processing techniques have also been attempted to compensate those defects in different ionic oxides. However, as already mentioned above with regard to the thermal anneal in forming gas ambience, post growth processing which often involves annealing at high temperature sometimes degrades the overall electrical properties due to the formation of interfacial layers with inferior dielectric constants. ${ }^{67,68}$ Alternatively, incorporation of dopants has been reported to be a viable route to improve the electrical properties of different oxides by reducing the influence of $\mathrm{V}_{\mathrm{O}} \mathrm{s}$. For example, first principle calculations suggested that nitrogen $(\mathrm{N})$ incorporation in $\mathrm{Hf}$ based dielectrics can reduce the leakage current conduction by effectively deactivating $\mathrm{V}_{\mathrm{O}} \mathrm{S}$ related gap states. ${ }^{69}$ Substantial improvement of electrical properties has also been reported for $\mathrm{HfO}_{2}$ thin films doped with fluorine, nitrogen, or lanthanum. ${ }^{70-72}$

To explore the possible influence of dopants on the electrical properties of epitaxial $\mathrm{Ln}_{2} \mathrm{O}_{3} \mathrm{~s}$, we investigated the influence of nitrogen incorporation on the dielectric properties of epitaxial $\mathrm{Gd}_{2} \mathrm{O}_{3}$ layers. Nitridation of the layers was achieved by using nonactivated molecular $\mathrm{N}_{2} \mathrm{O}$ as process gas instead of $\mathrm{O}_{2}$ during growth. The incorporation of nitrogen into the oxide layers was checked by secondary ion mass spectroscopy (SIMS). The formation of $\mathrm{Gd}-\mathrm{N}$ bonds in the $\mathrm{Gd}_{2} \mathrm{O}_{3}$ : $\mathrm{N}$ layers was confirmed by in situ XPS measurements from the chemical shift of the $\mathrm{Gd} 4 d$ peaks toward lower binding energy compared to pure $\mathrm{Gd}_{2} \mathrm{O}_{3}$ layers. ${ }^{73}$ However, a quantitative estimation of the $\mathrm{N}$ incorporated into the $\mathrm{Gd}_{2} \mathrm{O}_{3}$ layers by this approach is yet to be achieved. Layers with different amount of $\mathrm{N}$ were grown by maintaining different partial pressure of $\mathrm{N}_{2} \mathrm{O}\left(P_{\mathrm{N}_{2} \mathrm{O}}\right)$

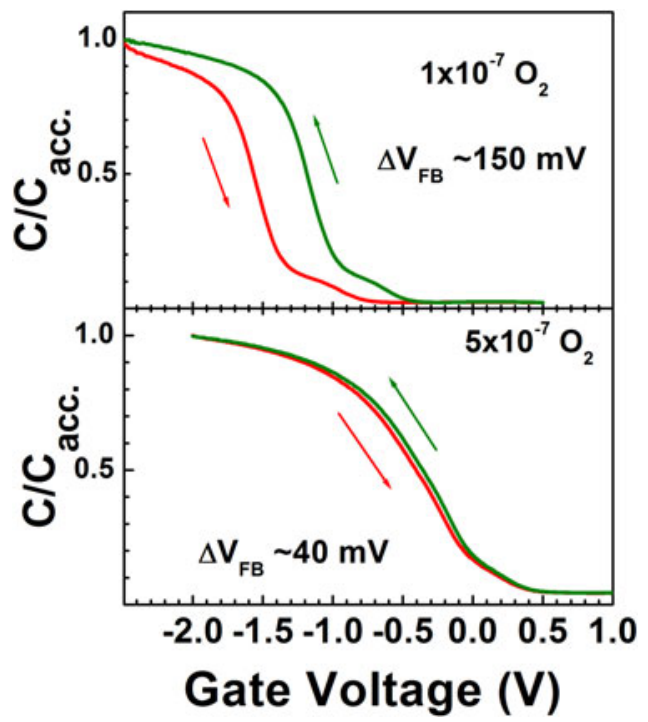

FIG. 16. $C-V$ characteristics of two epitaxial $\mathrm{Gd}_{2} \mathrm{O}_{3}$ layers on $\mathrm{Si}(001)$ substrates grown at different oxygen partial pressures. during deposition. All $\mathrm{Gd}_{2} \mathrm{O}_{3}: \mathrm{N}$ samples grown with different $P_{\mathrm{N}_{2} \mathrm{O}}$ exhibited similar uniform distribution of $\mathrm{N}$ concentration across the oxide layer. Figure 17 displays the SIMS profile of a representative $\mathrm{Gd}_{2} \mathrm{O}_{3}: \mathrm{N}$ sample which confirms the presence of $\mathrm{N}$ inside the oxide layer.

Further, to understand the impact of $\mathrm{N}$ incorporation on the growth of $\mathrm{Gd}_{2} \mathrm{O}_{3}$ and the electrical properties of MOS stacks with epitaxial $\mathrm{Gd}_{2} \mathrm{O}_{3}: \mathrm{N}$ on $\mathrm{Si}$, these layers were compared with control $\mathrm{Gd}_{2} \mathrm{O}_{3}$ layers grown with similar partial pressure of molecular oxygen. ${ }^{73,74}$ The streaky RHEED patterns [Fig. 18(a)] exhibited by the $\mathrm{Gd}_{2} \mathrm{O}_{3}$ : $\mathrm{N}$ layer surface indicate the same two-dimensional growth on $\mathrm{Si}(111)$ as observed for undoped oxide. Figure $18(\mathrm{~b})$ compares the X-ray diffraction patterns of two $\mathrm{Gd}_{2} \mathrm{O}_{3}: \mathrm{N}$ layers grown at different $\mathrm{N}_{2} \mathrm{O}$ partial pressures with a control $\mathrm{Gd}_{2} \mathrm{O}_{3}$ layer in the $\theta-2 \theta$ geometry. The shoulder observed at $2 \theta \sim 28.9^{\circ}$ beside the $\mathrm{Si}(111)$ peak corresponds to the (111) oriented epitaxial $\mathrm{Gd}_{2} \mathrm{O}_{3}$ with cubic bixbyite type of structure.

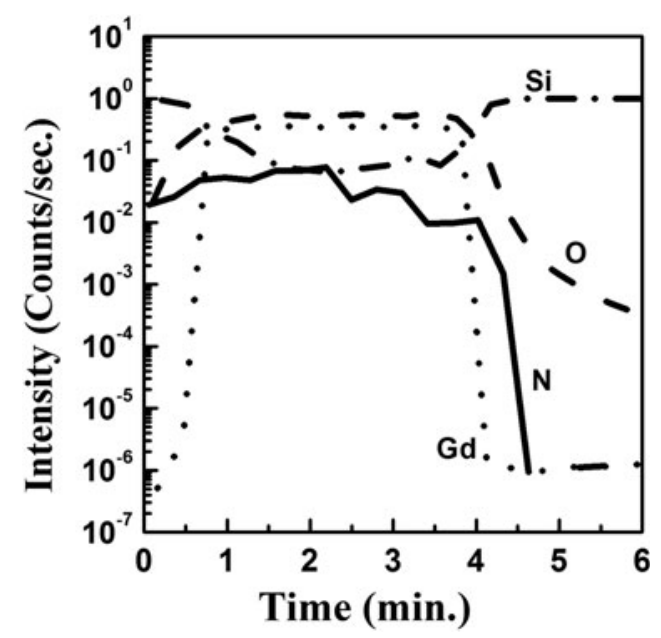

FIG. 17. SIMS depth profile of $\mathrm{Gd}, \mathrm{O}, \mathrm{N}$ and $\mathrm{Si}$ elements of a representative $\mathrm{Gd}_{2} \mathrm{O}_{3}: \mathrm{N}$ sample as function of etching time.

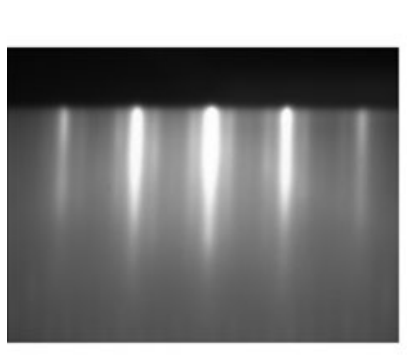

(a)

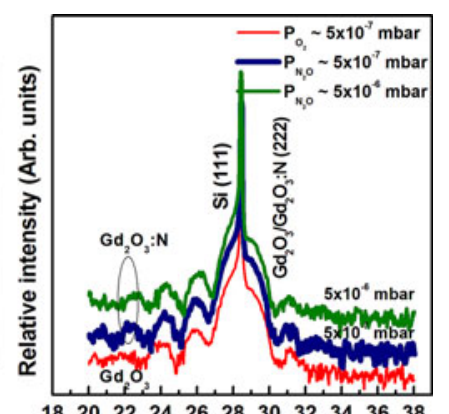

(b)
$2 \theta$ (degrees)
FIG. 18. (a) RHEED pattern along the $\langle 110\rangle$ azimuth of a representative $\mathrm{Gd}_{2} \mathrm{O}_{3}$ :N layer $\left(P_{\mathrm{N}_{2} \mathrm{O}} \sim 5 \times 10^{-7} \mathrm{mbar}\right)$ and (b) $\mathrm{X}$-ray diffraction patterns in the $\theta-2 \theta$ geometry of a control $\mathrm{Gd}_{2} \mathrm{O}_{3}$ layer and two representative $\mathrm{Gd}_{2} \mathrm{O}_{3}: \mathrm{N}$ layers. 
These results indicate that usage of $\mathrm{N}_{2} \mathrm{O}$ as a process gas incorporates $\mathrm{N}$ into the $\mathrm{Gd}_{2} \mathrm{O}_{3}$ layers only at a doping level and it does not affect the growth and structure of the layers.

However, a dramatic change in the dielectric properties of the epitaxial $\mathrm{Gd}_{2} \mathrm{O}_{3}$ layers was observed due to $\mathrm{N}$ incorporation. Figure 19 compares the $C-V$ characteristics of a $\mathrm{Gd}_{2} \mathrm{O}_{3}$ and a $\mathrm{Gd}_{2} \mathrm{O}_{3}$ : $\mathrm{N}$ sample grown under lower partial pressure of the process gases $\left(\sim 2 \times 10^{-7}\right.$ mbar $)$. The control sample prepared under reduced $P_{\mathrm{O}_{2}}$ [Fig. 19(a)] exhibits a strong hysteresis in the $C-V$ behavior inferring that there exist a large number of mobile oxide charges inside the oxide layer. A density of $Q_{\mathrm{m}} \sim 2 \times$ $10^{12} \mathrm{~cm}^{-2}$ was estimated from the hysteretic shift of the $V_{\mathrm{FB}}(\sim 140 \mathrm{mV})$ assuming only $Q_{\mathrm{m}}$ contribution to the $C-V$ hysteresis. In contrary, in case of $\mathrm{N}$ doping [Fig. 19(b)] hysteresis in $C-V$ was nearly vanished with $\Delta V_{\mathrm{FB}}<10 \mathrm{mV}$ corresponding to a $Q_{\mathrm{m}}<1 \times 10^{11} \mathrm{~cm}^{-2}$. This clearly demonstrates that nitridation of $\mathrm{Gd}_{2} \mathrm{O}_{3}$ even at a low level (lower $P_{\mathrm{N}_{2} \mathrm{O}}$ ) already results in a nearly ideal dielectric behavior, likely due to an effective compensation of mobile oxide charges.

The influence of doping by other species has also been investigated by introducing carbon into $\mathrm{Gd}_{2} \mathrm{O}_{3}$. C incorporation in different high- $k$ oxides was reported to improve their dielectric properties. ${ }^{75,76}$ In our investigation, incorporation of $\mathrm{C}$ into the epitaxial $\mathrm{Gd}_{2} \mathrm{O}_{3}$ layers was found to result also in a significant improvement in the dielectric properties of MOS structures (i.e., minimize $C-V$ hysteresis and lower leakage current density) for $\mathrm{C}$ concentration below $0.5 \%{ }^{47,77}$ However, at higher concentration, $\mathrm{C}$ segregates to the oxide/Si interface during growth. That leads to polycrystallinity and degradation of the electrical properties due to the formation of additional defects, ${ }^{47,66}$ which makes it less preferred choice for doping $\mathrm{Gd}_{2} \mathrm{O}_{3}$ compared to $\mathrm{N}$.

In addition to their impact on the dielectric properties, the dopants can also have significant influence on the electronic structure of high- $k$ oxides. For example, density functional calculations revealed that incorporation of $\mathrm{N}$ into high- $k$ oxides leads to a reduction of
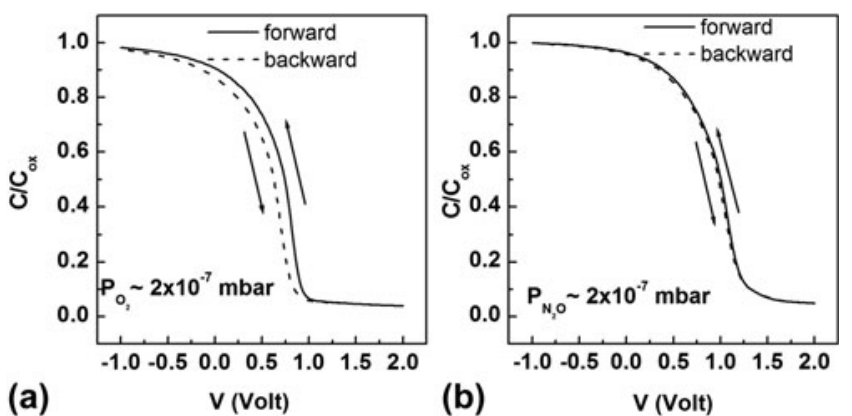

FIG. 19. Representative $C-V$ hysteresis curves corresponding to (a) a control epitaxial $\mathrm{Gd}_{2} \mathrm{O}_{3}$ samples and (b) an epitaxial $\mathrm{Gd}_{2} \mathrm{O}_{3}: \mathrm{N}$ sample. their band gap and the VBO with Si which could result in degradation of the MOS electrical properties. ${ }^{78}$ Therefore, to gain a holistic understanding, the impact of $\mathrm{N}$ incorporation into epitaxial $\mathrm{Gd}_{2} \mathrm{O}_{3}$ layers on its band structure and dc leakage properties were also investigated. The electronic structure of the oxide layers were probed using in situ XPS measurement. Valence band photoelectron spectra of the layers were used to estimate the impact of $\mathrm{N}$ doping on the $\mathrm{VBO}$ of $\mathrm{Gd}_{2} \mathrm{O}_{3}$ with $\mathrm{Si}$, which was determined from the relation:

$$
\Delta E_{\mathrm{V}}=\left(E_{\mathrm{CL}}^{\mathrm{Ox}}-E_{\mathrm{V}}^{\mathrm{Ox}}\right)-\left(E_{\mathrm{CL}}^{\mathrm{Si}}-E_{\mathrm{V}}^{\mathrm{Si}}\right)-\Delta E_{\mathrm{CL}}
$$

where $\left(E_{\mathrm{CL}}^{\mathrm{Ox}}-E_{\mathrm{V}}^{\mathrm{Ox}}\right)$ and $\left(E_{\mathrm{CL}}^{\mathrm{Si}}-E_{\mathrm{V}}^{\mathrm{Si}}\right)$ are the core level to valence band maximum (VBM) energy difference for bulk $\mathrm{Gd}_{2} \mathrm{O}_{3}$ or $\mathrm{Gd}_{2} \mathrm{O}_{3}: \mathrm{N}$ and $\mathrm{Si}$, respectively, and $\Delta E_{\mathrm{CL}}$ is the separation between a certain core level of the oxide (O $1 s)$ and $\mathrm{Si}(\mathrm{Si} 2 p)$. The parameters for $\mathrm{Si}$ were measured from an identical bare Si wafer. The Si $2 p$ peak position, measured under the presence of a thin oxide layers $(\sim 2 \mathrm{~nm})$ at the $\mathrm{Si}$ surface, was found to be independent on the nature and the partial pressure of the processing gas $\left(\mathrm{O}_{2}\right.$ or $\left.\mathrm{N}_{2} \mathrm{O}\right)$ applied during the epitaxial layer growth, and, moreover, no notable difference in the oxide peak position was observed for samples with different thicknesses. Since the VBM for $\mathrm{Si}$ was nearly zero, the VBO between $\mathrm{Gd}_{2} \mathrm{O}_{3}: \mathrm{N}$ or $\mathrm{Gd}_{2} \mathrm{O}_{3}$ and Si could be directly determined from the position of the VBM of the oxide layers on Si. Figure 20 presents the VB photoelectron spectra of a control $\mathrm{Gd}_{2} \mathrm{O}_{3}$ sample and $\mathrm{Gd}_{2} \mathrm{O}_{3}$ :N samples grown on $\mathrm{Si}$ at different $P_{\mathrm{N}_{2} \mathrm{O}}$. A value of $2.4 \pm 0.2 \mathrm{eV}$ was obtained for VBO for all control $\mathrm{Gd}_{2} \mathrm{O}_{3}$ samples grown at different $P_{\mathrm{O}_{2}}$, which is in good agreement to an earlier report. ${ }^{48}$ Doping of $\mathrm{Gd}_{2} \mathrm{O}_{3}$ with $\mathrm{N}$ leads to a reduction of the VBO with Si. Thereby, the VBO value of $\mathrm{Gd}_{2} \mathrm{O}_{3} \mathrm{~N}$ was found to reduce progressively with increasing $P_{\mathrm{N}_{2} \mathrm{O}}$ from $2.2 \pm 0.2 \mathrm{eV}$

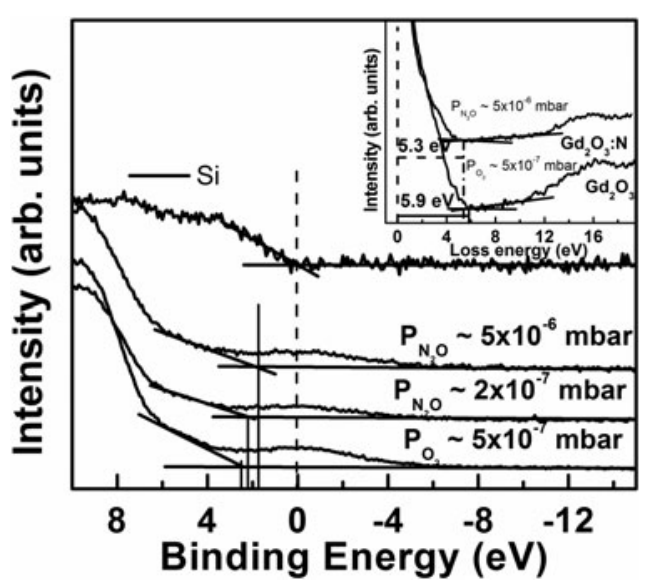

FIG. 20. Valence Band spectra for $\mathrm{Si}$, a control $\mathrm{Gd}_{2} \mathrm{O}_{3}$ layer and two $\mathrm{Gd}_{2} \mathrm{O}_{3}$ :N layers, (inset) $\mathrm{O} 1 s$ energy loss spectra of a control $\mathrm{Gd}_{2} \mathrm{O}_{3}$ layer and $\mathrm{Gd}_{2} \mathrm{O}_{3}: \mathrm{N}$ layer. 
for $P_{\mathrm{N}_{2} \mathrm{O}} \sim 2 \times 10^{-7}$ mbar up to a value of $1.7 \pm 0.2 \mathrm{eV}$ at $P_{\mathrm{N}_{2} \mathrm{O}} \sim 2 \times 10^{-6}$ mbar. Further increase of $P_{\mathrm{N}_{2} \mathrm{O}}$ did not influence the VBO under present experimental conditions, inferring saturation in the concentration of $\mathrm{N}$ incorporated into the $\mathrm{Gd}_{2} \mathrm{O}_{3}$ layer.

In further investigations, the band gaps of the $\mathrm{Gd}_{2} \mathrm{O}_{3}: \mathrm{N}$ and control $\mathrm{Gd}_{2} \mathrm{O}_{3}$ layers were estimated in XPS from the threshold energy of the plasmon energy loss spectrum observed at higher binding energy of the $\mathrm{O} 1 s$ core level peak, as already demonstrated for other metal oxides. ${ }^{26}$ As shown in the inset of Fig. 20, the extrapolation yields a band gap energy of $5.9 \pm 0.2 \mathrm{eV}$ for the control sample, which agrees very well to the previously reported values for epitaxial $\mathrm{Gd}_{2} \mathrm{O}_{3}$ layers on $\mathrm{Si}^{48}$ In contrast, the band gap of the $\mathrm{Gd}_{2} \mathrm{O}_{3}: \mathrm{N}$ layers was found to decrease from $5.7 \pm 0.2 \mathrm{eV}$ for a layer grown at $P_{\mathrm{N}_{2} \mathrm{O}} \sim 2 \times 10^{-7}$ mbar to $5.2 \pm 0.2 \mathrm{eV}$ for a layer grown at $P_{\mathrm{N}_{2} \mathrm{O}} \sim 2 \times 10^{-6}$ mbar.

The band gap narrowing and reduction in VBO of epi- $\mathrm{Gd}_{2} \mathrm{O}_{3}: \mathrm{N}$ with $\mathrm{Si}$ can be understood by considering the nature of the VB structure of the binary Ln sesquioxides. In case of the Ln sesquioxides the valence band maximum is formed mainly by the $\mathrm{O} 2 p$ states. ${ }^{79}$ In case of substitutional $\mathrm{N}$ incorporation in different lanthanide and transition metal oxides (e.g., $\mathrm{La}_{2} \mathrm{O}_{3}, \mathrm{HfO}_{2}$ ), their upper VB levels are shared between both $\mathrm{O} 2 p$ and $\mathrm{N} 2 p$ states. ${ }^{78}$ The energy level of the $\mathrm{N} 2 p$ states lie above the $\mathrm{O} 2 p$ states, which leads to a shift of the VBM toward higher energy, thereby reducing the VB offset of the $\mathrm{N}$ doped oxide layer with $\mathrm{Si}$. The same is valid for $\mathrm{Gd}_{2} \mathrm{O}_{3}$, the increase of $\mathrm{N}$ content in the $\mathrm{Gd}_{2} \mathrm{O}_{3}$ layers causes the VBM to possess increasing $\mathrm{N} 2 p$ character, which leads to the gradual reduction of the band gap and VBO with $\mathrm{Si}$, until saturation. The conduction band offsets (CBOs) estimated for the $\mathrm{Gd}_{2} \mathrm{O}_{3} / \mathrm{Si}$ structures considering the differences in the VBO, the energy gap of the $\mathrm{Si}$ substrate $(\sim 1.12 \mathrm{eV})$ and the measured band gap of the oxide were found to be nearly identical $(2.4 \pm 0.2 \mathrm{eV})$ for all the $\mathrm{Gd}_{2} \mathrm{O}_{3}$ and $\mathrm{Gd}_{2} \mathrm{O}_{3}$ :N samples; indicating that the $\mathrm{CB}$ of the oxide layers remains nearly unaffected by $\mathrm{N}$ doping, that agrees well with $a b$ initio calculations reported for related oxides. ${ }^{78}$

The reduction in the VBO with $\mathrm{Si}$ due to $\mathrm{N}$ incorporation can be expected to degrade the insulating properties of the $\mathrm{Gd}_{2} \mathrm{O}_{3}: \mathrm{N}$ layer owing to lower hole barrier. However, as demonstrated for a representative set of samples in Fig. 21(a), the room temperature dc leakage measurements revealed that at applied electric fields below $4 \mathrm{MV} / \mathrm{cm}$ all the $\mathrm{Gd}_{2} \mathrm{O}_{3}: \mathrm{N}$ samples grown under different $P_{\mathrm{N}_{2} \mathrm{O}}$ exhibit lower leakage current densities compared to the control $\mathrm{Gd}_{2} \mathrm{O}_{3}$ samples grown under similar $P_{\mathrm{O}_{2}}$ indicating their superior insulating properties. For example, at $1 \mathrm{~V}\left(V_{\mathrm{FB}}-1 \mathrm{~V}\right)$, the leakage current densities of the $\mathrm{Gd}_{2} \mathrm{O}_{3}: \mathrm{N}$ layers were found to be about

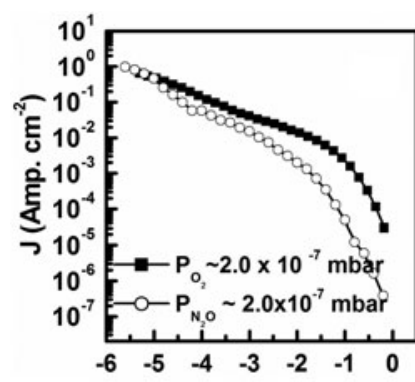

(a)

$\mathrm{E}(\mathrm{MV} / \mathrm{cm})$

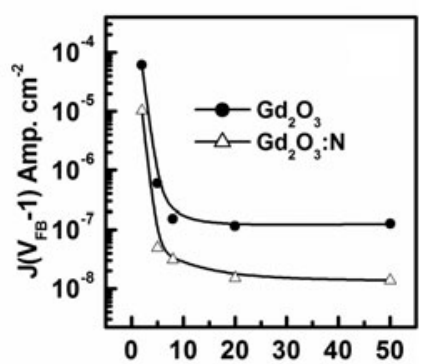

(b)

$P_{\mathrm{x}}\left(\times 10^{-7}\right)$ (mbar)
FIG. 21. (a) Room temperature dc leakage current densities of a representative $\mathrm{Gd}_{2} \mathrm{O}_{3}$ and a $\mathrm{Gd}_{2} \mathrm{O}_{3}: \mathrm{N}$ layer. (b) dc leakage current densities measured at $1 \mathrm{~V}$ for different $\mathrm{Gd}_{2} \mathrm{O}_{3}$ and $\mathrm{Gd}_{2} \mathrm{O}_{3}: \mathrm{N}$ samples as functions of ambient gas partial pressure $\left(P_{\mathrm{X}}\right)$ during growth. $\mathrm{X}$ denotes $\mathrm{O}_{2}$ in case $\mathrm{Gd}_{2} \mathrm{O}_{3}$ and $\mathrm{N}_{2} \mathrm{O}$ in case of $\mathrm{Gd}_{2} \mathrm{O}_{3}: \mathrm{N}$ layers. The lines are to guide the eyes.

one order of magnitude lower compared to the control samples [Fig. 21 (b)].

The superior insulating properties of the $\mathrm{Gd}_{2} \mathrm{O}_{3}: \mathrm{N}$ layers can be explained by considering the influence of $\mathrm{N}$ on the electrically active defects in $\mathrm{Gd}_{2} \mathrm{O}_{3}$, especially on $\mathrm{V}_{\mathrm{O}} \mathrm{S}$, which are the most dominating electrically active defect in complex oxides grown at higher temperatures. ${ }^{80,81}$ Experimental investigations and $a b$ initio calculations revealed that $\mathrm{V}_{\mathrm{O}}$ induce electron conduction paths in complex oxides which give rise to enhanced leakage current densities. ${ }^{82-85}$ The same can be suggested for epitaxial $\mathrm{Ln}_{2} \mathrm{O}_{3}$ s. In case of ionic oxides, this occurs via $\mathrm{V}_{\mathrm{O}} \mathrm{S}$ induced energy states within the band gap, which are occupied by two electrons for the neutral vacancy $\left(V_{\mathrm{O}}^{0}\right)$ and are strongly localized on the orbitals of the adjacent metal ions. ${ }^{66,80,83}$ Moreover, migration of $\mathrm{V}_{\mathrm{O}} \mathrm{S}$ under sufficiently large electric field can also give rise to an increase in the leakage current densities in complex oxides. ${ }^{86-88}$ Lowering of the leakage current densities by incorporation of $\mathrm{N}$ into $\mathrm{Gd}_{2} \mathrm{O}_{3}$ layers can be understood in much the same way as the elimination of the hysteresis effect in $C-V$ measurements of nitrogen-doped $\mathrm{Gd}_{2} \mathrm{O}_{3}$ by considering the specific role of $\mathrm{N}$ in compensating the adverse effects the $\mathrm{V}_{\mathrm{O}}$ s related defects. In analogy to the effect of $\mathrm{N}$ incorporation in various other ionic oxides, this can only happen either due to the formation of $\mathrm{N}-\mathrm{V}_{\mathrm{O}} \mathrm{S}$ complexes and/or substitution of the $\mathrm{V}_{\mathrm{O}} \mathrm{S}$ by $\mathrm{N}$ atoms in the $\mathrm{Gd}_{2} \mathrm{O}_{3}: \mathrm{N}$. First principle calculations of $\mathrm{N}$ incorporation in different oxides suggested that in a minimum free energy configuration two $\mathrm{N}$ atoms occupy the nearest neighbor $\mathrm{O}$ sites to $\mathrm{V}_{\mathrm{O}} \mathrm{S} .{ }^{69,89}$ In this arrangement each $\mathrm{N}$ atom extracts one electron from the neutral $\mathrm{V}_{\mathrm{O}}$ sites to form a closed shell electronic configuration. Consequently, neutral $\mathrm{V}_{\mathrm{O}} \mathrm{s}$ transform into positively charged $\mathrm{V}_{\mathrm{O}}{ }^{2+}$ forming electric dipoles, which effectively elevates the energy of the $V_{O}$ related gap states above the conduction band of these oxides. In this way the dc leakage conduction is reduced. ${ }^{69,80}$ 
In analogy, the observed improvement in the dielectric properties of the $\mathrm{Gd}_{2} \mathrm{O}_{3}: \mathrm{N}$ layers could be attributed to a similar mechanism when $\mathrm{N}$ atoms combine favourably to the $\mathrm{V}_{\mathrm{O}}$ sites in $\mathrm{Gd}_{2} \mathrm{O}_{3}$ and modify their charge states. Moreover, $\mathrm{N}$ atoms can also immobilize the $\mathrm{V}_{\mathrm{O}}$ s which can in turn reduce the $\mathrm{V}_{\mathrm{O}}$ s motion related leakage current conduction under an applied electric field. ${ }^{69}$ The effect gets more pronounced with increasing $\mathrm{N}$ content in the $\mathrm{Gd}_{2} \mathrm{O}_{3}$ :N layers grown at higher $P_{\mathrm{N}_{2} \mathrm{O}}$. Further, the electric field corresponding to dielectric breakdown was found to be in the range of $4.5-5 \mathrm{MV} / \mathrm{cm}$ for all the samples, which agrees to the thermochemical description of dielectric breakdown in high- $k$ materials. ${ }^{90,91}$ However, in case of the $\mathrm{Gd}_{2} \mathrm{O}_{3}: \mathrm{N}$ layers the breakdown field was found to reduce with increasing $\mathrm{N}$ content. Such reduction in the dielectric breakdown field could be attributed to a collective effect of the reduced VB offset and an enhanced local electric field in the $\mathrm{Gd}_{2} \mathrm{O}_{3}$ layer due to $\mathrm{N}$ incorporation. ${ }^{90,91}$

\section{SUMMARY AND OUTLOOK}

We discussed different ways of growth optimization for improvement of dielectric properties of insulating $\mathrm{Ln}_{2} \mathrm{O}_{3}$ epitaxial grown on $\mathrm{Si}$ using molecular beam epitaxy. The growth optimization and discussion involves the density of charge defects inside the oxide layer as well as the oxide/Si interface, their impacts on the dielectric properties of oxide/Si heterostructures and different methods to passivate the charge defects. As a standard material we have considered epitaxial $\mathrm{Gd}_{2} \mathrm{O}_{3}$ layers to discuss the proof of principles. We demonstrated that the best vacuum condition achieved in the MBE chamber during oxide layer growth $\left(\sim 10^{-8}\right.$ mbar $)$ leads to silicide formation at the interface, which degrades the dielectric properties of the oxide layers. A controlled supply of molecular oxygen during the growth improves the interface quality significantly, however too high oxygen partial pressure leads to formation of lower permittivity interfacial layer and finally limits the achievable minimum effective oxide thickness. Partial pressure of oxygen in the range $10^{-7}$ mbar was found to be optimal to achieve epitaxial layers having atomic sharp interface to $\mathrm{Si}$. Although such layers exhibit good dielectric properties in terms of the effective oxide thickness, as grown epitaxial $\mathrm{Ln}_{2} \mathrm{O}_{3}$ s exhibit strong shift of the flatband voltage toward negative gate bias direction and also suffer from hysteretic flat band instability which render them unsuitable for transistor applications. In view of understanding the origin of flat band instability, we discussed the nature of fixed oxide charges in the epitaxial layers and their impact on the dielectric properties. The unsaturated dangling bond states in the oxide/Si interface were found to be responsible for the creation of positive charges inside the oxide layer, since they captures electrons form the oxide layer near to the interface. In addition to the fixed oxide charges, interface traps and mobile oxide charges originating from omnipresent oxygen vacancy related defect states also degrade the dielectric properties of the oxides. Consequently, these defects are required to be minimized prior to integrating these oxides into the $\mathrm{Si}$ technology for device application.

We have discussed different possible methods of defect passivation, such as annealing, doping and surface passivation by foreign atoms. Annealing the $\mathrm{Ln}_{2} \mathrm{O}_{3}$ layers in forming gas ambience, which is one of the most commonly used method for defect passivation in microelectronic materials, stands inadequate due to its sensitivity to the type of the metal gate used. As a viable alternative to this approach we have demonstrated that few monolayers of chemisorbed $\mathrm{Ge}$ or $\mathrm{C}$ on $\mathrm{Si}$ surface significantly improves the electrical properties of MOS structures with epitaxial $\mathrm{Gd}_{2} \mathrm{O}_{3}$ layers by passivation the Si dangling bond states. This happens due to the charge transfer from the dangling bonds of $\mathrm{Si}$ to the $\mathrm{Ge}$ or $\mathrm{C}$ atoms owing to the difference in their electronegativity. The passivation of the fixed oxide charges and interface traps stabilizes the flat band voltage and reduces hysteresis. Moreover, the flat band voltage can be tuned systematically by precisely controlling the amount of the chemisorbed species.

Incorporation of nitrogen into the oxide layers in a doping level was found to be a suitable way for passivation mobile oxide charges inside the layers, which results in vanishing flat band voltage hysteresis. Incorporation of $\mathrm{N}$ into the epitaxial $\mathrm{Gd}_{2} \mathrm{O}_{3}$ layer results in a band gap narrowing, which is related to the shift of valence band edge in $\mathrm{Gd}_{2} \mathrm{O}_{3}: \mathrm{N}$ layers toward higher energy due to their presumably increasing $\mathrm{N} 2 p$ character in the valence band edge. Despite the declining VBOs with $\mathrm{Si}$, the dc leakage current densities of epitaxial $\mathrm{Gd}_{2} \mathrm{O}_{3}$ layers is reduced significantly by $\mathrm{N}$ doping. These observations suggest that $\mathrm{N}$ incorporation in a doping level can improve the overall electrical properties of epitaxial $\mathrm{Ln}_{2} \mathrm{O}_{3}$ s by passivation the detrimental effects of the electrically active $\mathrm{V}_{\mathrm{O}}$ s related defect states. Therefore, it appears that suitably doped epitaxial $\mathrm{Ln}_{2} \mathrm{O}_{3}$ layers deposited on surface $\mathrm{Si}$ surfaces, which are passivized with chemisorbed $\mathrm{Ge}$, can be ideal candidate materials for next generation high- $k$ dielectric applications. However, it should be noted that the extent to which the band gap of $\mathrm{Gd}_{2} \mathrm{O}_{3}: \mathrm{N}$ and its band offsets with $\mathrm{Si}$ can be tuned by increasing the $\mathrm{N}$ doping concentration still remains unclear. Furthermore, the impact of oxide doping and oxide/Si modification by Ge predeposition in active devices, such as CMOS based FET, is not yet tested in practice.

\section{ACKNOWLEDGMENT}

This paper reviews research results we have been working on for the last 10 years at the Institute of 
Electronic Materials and Devices, Leibniz University Hannover. We are grateful to all PhD students and scientist working with us on particular aspects of that challenging project. We also would like to thank all partners and friends in Germany and all over the world for intense collaboration and help. Finally, we acknowledge the support of various organisations, in particular DFG (Deutsche Forschungsgemeinschaft), BMBF (Bundesministerium für Forschung und Technologie), DAAD (Deutscher Akademischer Austauschdienst), Humboldt Foundation, and GIF (German-Israel Foundation for Scientific Research and Development).

\section{REFERENCES}

1. G.E. Moore: Cramming more components onto integrated circuits. Electronics 38, 114ff (1965).

2. M.L. Green, E.P. Gusev, R. Degraeve, and E.L. Garfunkel: Ultrathin $(<4 \mathrm{~nm}) \mathrm{SiO}_{2}$ and $\mathrm{Si}-\mathrm{O}-\mathrm{N}$ gate dielectric layers for silicon microelectronics: Understanding the processing, structure, and physical and electrical limits. J. Appl. Phys. 90, 2057 (2001).

3. G. Pahionni: Defects in $\mathrm{SiO}_{2}$ and related dielectrics: Science and Technology (Kluwer Academic Publishers, Dordrecht, 2000); p. 1.

4. H.J. Osten, M. Czernohorsky, R. Dargis, A. Laha, D. Kuehne, E. Bugiel, and A. Fissel: Integration of functional epitaxial oxides into silicon: From high- $k$ application to nanostructures. Microelectron. Eng. 84, 2222 (2007).

5. G. Timp, J. Bude, K.K. Bourdelle, J. Garno, A. Ghetti, H. Gossmann, M. Green, G. Forsyth, Y. Kim, R. Kleiman, F. Klemens, A. Kornblit, C. Lochstampfor, W. Mansfield, S. Moccio, T. Sorsch, D.M. Tennant, W. Timp, and R. Tung: The ballistic nano-transistor. IEDM Tech. Dig. 99, 55 (1999).

6. The latest edition of the ITRS road map can be found at http:/ www.itrs2.net.

7. Z.J. Ma, J.C. Chen, Z.H. Liu, J.T. Crick, Y.C. Cheng, C. Hu, and P.K. Ko: Suppression of boron penetration in $\mathrm{P}^{+}$polysilicon gate P-MOSFET's using low-temperature gate-oxide $\mathrm{N}_{2} \mathrm{O}$ anneal. IEEE Electron Device Lett. 15, 109 (1994).

8. M. Cao, P.V. Voorde, M. Cox, and W. Greene: Boron diffusion and penetration in ultrathin oxide with poly-Si gate. IEEE Electron Device Lett. 19, 291 (1998).

9. J. Robertson: High dielectric constant gate oxides for metal oxide Si transistors. Rep. Prog. Phys. 69, 327 (2006).

10. E.P. Gusev, H-C. Lu, E.L. Garfunkel, T. Gustafsson, and M.L. Green: Growth and characterization of ultrathin nitrided silicon oxide films. IBM J. Res. Dev. 43, 265 (1999).

11. J.D. Plummer and P.B. Griffin: Material and process limits in silicon VLSI technology. Proc. IEEE 89, 240 (2001).

12. G.D. Wilk, R.M. Wallace, and J.M. Anthony: High- $k$ gate dielectrics: Current status and materials properties considerations. Appl. Phys. Rev. 89, 5243 (2001).

13. K.J. Hubbard and D.G. Schlom: Thermodynamic stability of binary oxides in contact with silicon. J. Mater. Res. 11, 2757 (1996).

14. K. Cho: First-principles modeling of high- $k$ gate dielectric materials. Comput. Mater. Sci. 23, 43 (2002).

15. J. Robertson: Band offsets of wide-band-gap oxides and implications for future electronic devices. J. Vac. Sci. Technol., B. Microelectron. Nanometer Struct. 18, 1785 (2000)

16. J. Lucovsky: Transition from thermally grown gate dielectrics to deposited gate dielectrics for advanced silicon devices: A classi- fication scheme based on bond ionicity. J. Vac. Sci. Technol., A 19, 1553 (2001).

17. G.D. Wilk and R.M. Wallace: Electrical properties of hafnium silicate gate dielectrics deposited directly on silicon. Appl. Phys. Lett. 74, 2854 (1999).

18. R.J. Potter, P.A. Marshall, P.R. Chalker, S. Taylor, A.C. Jones, T.C.Q. Noakes, and P. Bailey: Characterization of hafnium aluminate gate dielectrics deposited by liquid injection metalorganic chemical vapor deposition. Appl. Phys. Lett. 84, 4119 (2004).

19. Z.M. Rittersma, E. Naburgh, T. Dao, A.H.C. Hendriks, W.F.A. Besling, E. Tois, E. Vainonen-Ahlgren, M. Tuominen, and S. Haukka: Physical and electrical properties of Zr-silicate dielectric layers deposited by atomic layer deposition. Electrochem. Solid-State Lett. 6, F21 (2003).

20. P.D. Kirsch, C.S. Kang, J. Lozano, J.C. Lee, and J.G. Ekerdt: Electrical and spectroscopic comparison of $\mathrm{HfO}_{2} / \mathrm{Si}$ interfaces on nitrided and unnitrided Si(100). J. Appl. Phys. 91, 4353 (2002).

21. K. Mistry, C. Allen, C. Auth, B. Beattie, D. Bergstrom, M. Bost, M. Brazier, M. Buehler, A. Cappellani, R. Chau, C-H. Choi, G. Ding, K. Fischer, T. Ghani, R. Grover, W. Han, D. Hanken, M. Hattendorf, J. He, J. Hicks, R. Huessner, D. Ingerly, P. Jain, R. James, L. Jong, S. Joshi, C. Kenyon, K. Kuhn, K. Lee, H. Liu, J. Maiz, B. McIntyre, P. Moon, J. Neirynck, S. Pae, C. Parker, D. Parsons, C. Prasad, L. Pipes, M. Prince, P. Ranade, T. Reynolds, J. Sandford, L. Shifren, J. Sebastian, J. Seiple, D. Simon, S. Sivakumar, P. Smith, C. Thomas, T. Troeger, P. Vandervoorn, S. Williams, and K. Zawadzki: A $45 \mathrm{~nm}$ logic technology with high- $k+$ metal gate transistors, strained silicon, $9 \mathrm{Cu}$ interconnect layers, $193 \mathrm{~nm}$ dry patterning, and $100 \% \mathrm{~Pb}-$ free packaging. Proc. Tech. Dig. Int. Electron Dev. Meeting, 247 (2007).

22. H.J. Osten, A. Laha, M. Czernohorsky, E. Bugiel, R. Dargis, and A. Fissel: Introducing crystalline rare-earth oxides into $\mathrm{Si}$ technologies. Phys. Status Solidi A 205, 695 (2008).

23. G.V. Samsonov: The Oxide Handbook, 2nd ed. (IFI/Plenum, New York, 1982).

24. J. Robertson and K. Xiong: Electronic structure and band offsets of lanthanide oxides. Top. Appl. Phys. 106, 313 (2007).

25. M. Foëx and J.P. Traverse: Investigations about crystalline transformation in rare earths sesquioxides at high temperatures (in French). Rev. Int. Hautes Temp. Refract. 3, 429 (1966).

26. H. Nohira, W. Tsai, W. Besling, E. Young, J. Petry, T. Conard, W. Vandervorst, S. De Gendt, M. Heyns, J. Maes, and M. Tuominen: Characterization of ALCVD- $\mathrm{Al}_{2} \mathrm{O}_{3}$ and $\mathrm{ZrO}_{2}$ layer using X-ray photoelectron spectroscopy. J. Non-Cryst. Solids $\mathbf{3 0 3}$ 83 (2002).

27. M. Badylevich, S. Shamuilia, V.V. Afanas'ev, A. Stesmans, A. Laha, H.J. Osten, and A. Fissel: Investigation of the electronic structure at interfaces of crystalline and amorphous $\mathrm{Gd}_{2} \mathrm{O}_{3}$ thin layers with silicon substrates of different orientations. Appl. Phys. Lett. 90, 252101 (2007).

28. A. Roy Chaudhuri, A. Fissel, and H.J. Osten: Superior dielectric properties for template assisted grown (100) oriented $\mathrm{Gd}_{2} \mathrm{O}_{3}$ thin films on Si(100). Appl. Phys. Lett. 104, 012906 (2014).

29. A. Fissel, Z. Elassar, O. Kirfel, E. Bugiel, M. Czernohorsky, and H.J. Osten: Interface formation during molecular beam epitaxial growth of neodymium oxide on silicon. J. Appl. Phys. 99, 074105 (2006).

30. A. Fissel, H.J. Osten, and E. Bugiel: Towards understanding epitaxial growth of alternative high-KK dielectrics on $\mathrm{Si}(001)$ : Application to praseodymium oxide. J. Vac. Sci. Technol., B. Microelectron. Nanometer Struct. 21, 1765 (2003)

31. H.J. Osten, J.P. Liu, E. Bugiel, H.J. Mussig, and P. Zaumseil: Growth of crystalline praseodymium oxide on silicon. J. Cryst. Growth 235, 229 (2002). 
32. F.P. Netzer: Rare earth overlayers on silicon. J. Phys.: Condens. Matter 7, 991 (1995).

33. D.P. Norton, C. Park, Y.E. Lee, and J.D. Budai: Strontium silicide termination and silicate epitaxy on (001). J. Vac. Sci. Technol., B: Microelectron. Nanometer Struct. 20, 257 (2002).

34. A. Fissel, J. Dabrowski, and H.J. Osten: Photoemission and ab initio theoretical study of interface and film formation during epitaxial growth and annealing of praseodymium oxide on Si(001). J. Appl. Phys. 91, 8986 (2002).

35. E. Bugiel, H.J. Osten, A. Fissel, O. Kirfel, and M. Czernohosky: TEM investigations of epitaxial high- $k$ dielectrics on silicon. Microscopy of Semiconducting Materials 107, 343 (2005).

36. D. Schmeißer, J. Dabrowski, and H.J. Müssig: $\operatorname{Pr}_{2} \mathrm{O}_{3} / \mathrm{Si}(001)$ interface reactions and stability. Mater. Sci. Eng., B 109, 30 (2004).

37. M. Czernohorsky, E. Bugiel, H.J. Osten, A. Fissel, and O. Kirfel: Impact of oxygen supply during growth on the electrical properties of crystalline $\mathrm{Gd}_{2} \mathrm{O}_{3}$ thin films on $\mathrm{Si}(001)$. Appl. Phys. Lett. 88, 152905 (2006)

38. H.D.B. Gottlob, T. Echtermeyer, M. Schmidt, T. Mollenhauer, J.K. Efavi, T. Wahlbrink, M.C. Lemme, M. Czernohorsky, E. Bugiel, A. Fissel, H.J. Osten, and H. Kurz: 0.86-nm CET gate stacks with epitaxial $\mathrm{Gd}_{2} \mathrm{O}_{3}$ high- $k$ dielectrics and FUSI NiSi metal electrodes. IEEE Electron Device Lett. 27, 814 (2006).

39. Q.Q. Sun, A. Laha, S.J. Ding, D.W. Zhang, H.J. Osten, and A. Fissel: Effective passivation of slow interface states at the interface of single crystalline $\mathrm{Gd}_{2} \mathrm{O}_{3}$ and $\mathrm{Si}(100)$. Appl. Phys. Lett. 92, 152908 (2008).

40. A. Laha, A. Fissel, and H.J. Osten: Effect of Ge passivation on interfacial properties of crystalline $\mathrm{Gd}_{2} \mathrm{O}_{3}$ thin films grown on $\mathrm{Si}$ substrates. Appl. Phys. Lett. 96, 072903 (2010).

41. G.S. Lujan, W. Magnus, L.A. Ragnarsson, S. Kubicek, S.D. Gendt, M. Heyns, and K.D. Meyer: Modelling mobility degradation due to remote Coulomb scattering from dielectric charges and its impact on MOS device performance. Microelectron. Reliab. 45, 794 (2005).

42. M. Casse, L. Thevenod, B. Guillaumot, L. Tosti, F. Martin, J. Mitard, O. Weber, F. Andrieu, T. Ernst, G. Reimbold, T. Billon, M. Mouis, and F. Boulanger: Carrier transport in $\mathrm{HfO}_{2} /$ metal gate MOSFETs: Physical insight into critical parameters. IEEE Trans. Electron Devices 53, 759 (2006).

43. A.N. Nazarov, Y.V. Gomeniuk, Y.Y. Gomeniuk, H.D.B. Gottlob, M. Schmidt, M.C. Lemme, M. Czernohorsky, and H.J. Osten: Charge trapping in ultrathin $\mathrm{Gd}_{2} \mathrm{O}_{3}$ high- $k$ dielectric. Microelectron. Eng. 84, 1968 (2007).

44. K. Xiong, J. Robertson, M. Gibson, and S.J. Clark: Defect energy levels in $\mathrm{HfO}_{2}$ high-dielectric-constant gate oxide. Appl. Phys. Lett. 87, 183505 (2005).

45. K. Xiong, J. Robertson, and S.J. Clark: Defect states in the highdielectric-constant gate oxide $\mathrm{LaAlO}_{3}$. Appl. Phys. Lett. 89, 022907 (2006)

46. G. Holzlechner, D. Kastner, C. Slouka, H. Hutter, and J. Feig: Oxygen vacancy redistribution in $\mathrm{PbZr}_{x} \mathrm{Ti}_{1-x} \mathrm{O}_{3}$ (PZT) under the influence of an electric field. Solid State Ionics 262, 625 (2014).

47. A. Laha, B. Ai, P.R.P. Babu, A. Fissel, and H.J. Osten: Impact of carbon incorporation into epitaxial $\mathrm{Gd}_{2} \mathrm{O}_{3}$ thin films on silicon: An experimental study on electrical properties. Appl. Phys. Lett. 99, 152902 (2011)

48. A. Laha, H.J. Osten, and A. Fissel: Influence of interface layer composition on the electrical properties of epitaxial $\mathrm{Gd}_{2} \mathrm{O}_{3}$ thin films for high-K application. Appl. Phys. Lett. 90, 113508 (2007).

49. N. Wu, Q. Zhang, C. Zhu, D.S.H. Chan, M.F. Li, N. Balasubramanian, A. Chin, and D.L. Kwong: Alternative surface passivation on germanium for metal-oxidesemiconductor applications with high- $k$ gate dielectric. Appl. Phys. Lett. 85, 4127 (2004).
50. M. Houssa, G. Pourtois, B. Kaczer, B.D. Jaeger, F.E. Leys, D. Neils, K. Paredis, A. Vantomme, M. Caymax, M. Meuris, and M.M. Heyns: Experimental and theoretical study of $\mathrm{Ge}$ surface passivation. Microelectron. Eng. 84, 2267 (2007).

51. N. Taoka, M. Harada, Y. Yamashita, T.T. Yamamoto, N. Sugiyama, and S.I. Takagi: Effects of Si passivation on Ge metal-insulator-semiconductor interface properties and inversionlayer hole mobility. Appl. Phys. Lett. 92, 113511 (2008).

52. H.F. Ma, Z.H. Qin, M.C. Xu, D.X. Shi, H-J. Gao, S. Wang, and S.T. Pantelides: formation and evolution of a self-organized hierarchy of Ge nanostructures on $\operatorname{Si}(111)-(7 \times 7)$ : STM observations and first-principles calculations. Phys. Rev. B: Condens. Matter Mater. Phys. 75, 165403 (2007).

53. A. Laha, H.J. Osten, and A. Fissel: Impact of $\mathrm{Si}$ substrate orientations on electrical properties of crystalline $\mathrm{Gd}_{2} \mathrm{O}_{3}$ thin films for high-K application. Appl. Phys. Lett. 89, 143514 (2006).

54. J.E. Rowe and H. Ibach: Surface and bulk contributions to ultraviolet photoemission spectra of silicon. Phys. Rev. Lett. 32, 421 (1974).

55. R.I.G. Uhrberg, G.V. Hansson, J.M. Nicholls, P.E.S. Persson, and S.A. Flodström: Photoemission study of the surface and bulk electronic structures of $\mathrm{Si}(111) 7 \times 7$ and $\mathrm{Si}(111) \sqrt{3} \times \sqrt{3}$ :Al. Phys. Rev. B: Condens. Matter Mater. Phys. 31, 3805 (1985).

56. J.A. Carlisle, T. Miller, and T-C. Chaing: Ge chemisorption and alloying on the $\operatorname{Si}(111)-(7 \times 7)$ surface. Phys. Rev. B: Condens. Matter Mater. Phys. 49, 13600 (1994).

57. P. Martensson, W.X. BNi, G.V. Hansson, J. Michael Nicholls, and B. Reihl: Surface electronic structure of $\mathrm{Si}(111) 7 \times 7-\mathrm{Ge}$ and $\mathrm{Si}(111) 5 \times 5$-Ge studied with photoemission and inverse photoemission. Phys. Rev. B: Condens. Matter Mater. Phys. 36, 5974 (1987).

58. K. Kajiyama, Y. Tanishiro, and K. Takayanagi: Reconstructions and phase transitions of $\mathrm{Ge}$ on the $\mathrm{Si}(111) 7 \times 7$ surface: I. Structural changes. Surf. Sci. 222, 38 (1989).

59. Y.L. Wang, H-J. Gao, H.M. Guo, S. Wang, and S.T. Pantelides: Bonding configurations and collective patterns of $\mathrm{Ge}$ atoms adsorbed on Si(111)-(7 × 7). Phys. Rev. Lett. 94, 106101 (2005).

60. M.C. Xu, H.F. Ma, W. Ji, B. Yang, and H-J. Gao: Growth of Ge hexagonal meshwork films on $\mathrm{Si}(111)-7 \times 7$. Nanotechnology 17 , 4413 (2006)

61. G. Pourtois, M. Houssa, B.D. Jaeger, B. Kaczer, F. Leys, M. Meuris, M. Caymax, G. Groeseneken, and M. Heyns: Threshold voltage shifts in Si passivated (100)Ge p-channel field effect transistors: Insights from first-principles modeling. Appl. Phys. Lett. 91, 023506 (2007).

62. E. Fontes, J.R. Patel, and F. Comin: Direct measurement of the asymmetric dimer buckling of $\mathrm{Ge}$ on $\mathrm{Si}(001)$. Phys. Rev. Lett. 70, 2790 (1993)

63. L. Patthey, F.L. Bullock, T. Abukawa, S. Kono, and L.S.O. Johansson: Mixed Ge-Si dimer growth at the $\mathrm{Ge} / \mathrm{Si}(001)$ $(2 \times 1)$ surface. Phys. Rev. Lett. 75, 2538 (1995).

64. H. Oyanagi, K. Sakamoto, R. Shioda, Y. Kuwahara, and K. Haga: Ge overlayers on $\mathrm{Si}(001)$ studied by surface-extended X-rayabsorption fine structure. Phys. Rev. B: Condens. Matter Mater. Phys. 52, 5824 (1995).

65. A. Laha, A. Fissel, and H.J. Osten: Effective control on flat band voltage of epitaxial lanthanide oxide based metal oxide semiconductor capacitors by interfacial carbon. Appl. Phys. Lett. 102, 202902 (2013).

66. P. Shekhter, A. Roy Chaudhuri, A. Laha, S. Yehezkel, A. Shriki, H.J. Osten, and M. Eizenberg: The influence of carbon doping on the performance of $\mathrm{Gd}_{2} \mathrm{O}_{3}$ as high- $k$ gate dielectric. Appl. Phys. Lett. 105, 262901 (2014).

67. G. Bonnet, M. Lachkar, J.C. Colson, and J.P. Larpin: Characterization of thin solid films of rare earth oxides formed by the 
metallo-organic chemical vapour deposition technique, for high temperature corrosion applications. Thin Solid Films 261, 31 (1995).

68. T.M. Pan, X-C. Wu, and L-C. Yen: Effects of postdeposition annealing on physical and electrical properties of high- $k \mathrm{Yb}_{2} \mathrm{TiO}_{5}$ dielectrics. J. Vac. Sci. Technol., A 28, 1084 (2010).

69. N. Umezawa, K. Shiraishi, T. Ohno, H. Watanabe, T. Chikyow, K. Torii, K. Yamabe, K. Yamada, H. Kitajima, and T. Arikado: First-principles studies of the intrinsic effect of nitrogen atoms on reduction in gate leakage current through Hf-based high- $k$ dielectrics. Appl. Phys. Lett. 86, 143507 (2005).

70. K. Seo, R. Sreenivasan, P. McIntyre, and K. Saraswat: Improvement in high- $k\left(\mathrm{HfO}_{2} / \mathrm{SiO}_{2}\right)$ reliability by incorporation of fluorine. IEEE Electron Device Lett. 27, 821 (2006).

71. C-H. Choi, S.J. Rhee, T.S. Jeon, N. Lu, J.H. Sim, R. Clark, M. Niwa, and D.L. Kwong: Thermally stable CVD $\mathrm{HfO}_{x} \mathrm{~N}_{y}$ advanced gate dielectrics with poly-Si gate electrode. In Digest. International Electron Devices Meeting (IEEE, Piscataway, 2002); p. 857.

72. X.P. Wanga, M.F. Lia, A. Chin, C.X. Zhu, J. Shao, W. Lu, X.C. Shen, X.F. Yu, R. Chi, C. Shen, A.C.H. Huan, J.S. Pan, A.Y. Du, P. Lo, D.S.H. Chan, and D.L. Kwong: Physical and electrical characteristics of high- $\kappa$ gate dielectric $\mathrm{Hf}_{(1-x)} \mathrm{La}_{x} \mathrm{O}_{y}$. Solid-State Electron. 50, 986 (2006).

73. A. Roy Chaudhuri, A. Fissel, V.R. Archakam, and H.J. Osten: Improving dielectric properties of epitaxial $\mathrm{Gd}_{2} \mathrm{O}_{3}$ thin films on silicon by nitrogen doping. Appl. Phys. Lett. 102, 022904 (2013).

74. A. Roy Chaudhuri, A. Fissel, and H.J. Osten: Investigation of band offsets and direct current leakage properties of nitrogen doped epitaxial $\mathrm{Gd}_{2} \mathrm{O}_{3}$ thin films on Si. J. Appl. Phys. 113, 184108 (2013).

75. G. Dutta, K.P.S.S. Hembram, G. Mohan Rao, and U.V. Waghmare: Effects of $\mathrm{O}$ vacancies and $\mathrm{C}$ doping on dielectric properties of $\mathrm{ZrO}_{2}$ : A first-principles study. Appl. Phys. Lett. 89, 202904 (2006).

76. K. Chu, J.P. Chang, M.L. Steigerwald, R.M. Flemimg, R.L. Opila, D.V. Lang, R.B. Van Dover, and C.D.W. Jones: Material and electrical characterization of carbon-doped $\mathrm{Ta}_{2} \mathrm{O}_{5}$ films for embedded dynamic random access memory applications. J. Appl. Phys. 91, 308 (2002).

77. A. Laha, A. Bin, P.R.P. Babu, A. Fissel, and H.J. Osten: Enhanced electrical properties of carbon doped epitaxial $\mathrm{Gd}_{2} \mathrm{O}_{3}$ thin films on Si substrates. ECS Trans. 41, 101 (2011).
78. G. Shang, P.W. Peacock, and J. Robertson: Stability and band offsets of nitrogenated high-dielectric-constant gate oxides. Appl. Phys. Lett. 84, 106 (2004).

79. R. Gillen, S.J. Clark, and J. Robertson: Nature of the electronic band gap in lanthanide oxides. Phys. Rev. B: Condens. Matter Mater. Phys. 87, 125116 (2013).

80. J. Robertson, K. Xiong, and S.J. Clark: Defect energy levels in high- $k$ gate oxides. In Defects in High-k Gate Dielectric Stacks NATO Science Series, Vol. 220, E. Gusev, ed. (Springer, The Netherlands, 2006); p. 175.

81. S. Guha and V. Naryan: Oxygen vacancies in high dielectric constant oxide-semiconductor films. Phys. Rev. Lett. 98, 196101 (2007).

82. R.M. Fleming, D.V. Lang, C.D.W. Jones, M.L. Steigerwald, D.W. Murphy, G.B. Alers, Y-H. Wong, R.b. van Dover, J.R. Kwo, and A.M. Sergent: Defect dominated charge transport in amorphous $\mathrm{Ta}_{2} \mathrm{O}_{5}$ thin films. J. Appl. Phys. 88, 850 (2000).

83. P. Broqvist and A. Pasquarello: Oxygen vacancy in monoclinic $\mathrm{HfO}_{2}$ : A consistent interpretation of trap assisted conduction, direct electron injection, and optical absorption experiments. Appl. Phys. Lett. 89, 262904 (2006).

84. K. Xiong and J. Robertson: Oxygen vacancies in high dielectric constant oxides $\mathrm{La}_{2} \mathrm{O}_{3}, \mathrm{Lu}_{2} \mathrm{O}_{3}$, and $\mathrm{LaLuO}_{3}$. Appl. Phys. Lett. 95, 022903 (2009).

85. D. Liu, S.J. Clark, and J. Robertson: Oxygen vacancy levels and electron transport in $\mathrm{Al}_{2} \mathrm{O}_{3}$. Appl. Phys. Lett. 96, 032905 (2010).

86. K. Tse, D. Liu, K. Xiong, and J. Robertson: Oxygen vacancies in high- $k$ oxides. Microelectron. Eng. 84, 2028 (2007).

87. R. Meyer, R. Liedtke, and R. Waser: Oxygen vacancy migration and time-dependent leakage current behavior of $\mathrm{Ba}_{0.3} \mathrm{Sr}_{0.7} \mathrm{TiO}_{3}$ thin films. Appl. Phys. Lett. 86, 112904 (2005).

88. J. Wang and S.T. McKinstry: Oxygen vacancy motion in Er-doped barium strontium titanate thin films. Appl. Phys. Lett. 89, 172906 (2006).

89. H. Li and J. Robertson: Defect compensation in $\mathrm{LaAlO}_{3}$ perovskite-based high dielectric constant oxides. J. Appl. Phys. 112, 034108 (2012)

90. J. McPherson, J-Y. Kim, A. Shanware, and H. Mogul: Thermochemical description of dielectric breakdown in high dielectric constant materials. Appl. Phys. Lett. 82, 2121 (2003).

91. J. McPherson, R.B. Khamankar, and A. Shanware: Complementary model for intrinsic time-dependent dielectric breakdown in $\mathrm{SiO}_{2}$ dielectrics. J. Appl. Phys. 88, 5351 (2000). 